\title{
International Trade and Employment: Theory and Evidence from Korean Firms
}

\author{
Priyaranjan Jha \\ University of California - Irvine \\ pranjan@uci.edu \\ Jae Yoon Lee \\ KIET \\ jaylee258@gmail.com \\ Yang Liang \\ San Diego State University \\ yang.liang@sdsu.edu \\ Devashish Mitra \\ Syracuse University \\ dmitra@maxwell.syr.edu
}

October, 2019

\begin{abstract}
We extend the small country trade model with firm heterogeneity (Demidova and RodriguezClare, 2013) to incorporate offshoring (along with final goods trade). We derive the firm-level employment implications of output and input trade and trade costs to provide a guide for our empirical work using Korean firm-level data for the period 2006-2016. A key theoretical result is that the impact of a change in offshoring cost on employment depends crucially on the net substitutability between inputs where net substitutability is the difference between the elasticities of input substitution and output substitution. Empirically we find that a decrease in the input trade cost reduces employment and the impact is stronger the greater the net substitutability between inputs. Exporting almost always leads to higher employment. Our 2SLS results with firm-level imports (in place of trade costs) do not contradict our results with trade costs. However, using propensity score matching, we find that being an importer, on average, is associated with greater employment, with the magnitude of this positive employment effect being greater for exporting firms and in industries with lower net substitutability among inputs.
\end{abstract}

Keywords: Offshoring, Employment, South Korea, Trade Costs, Net Input Substitutability JEL Codes: F12, F14, F16 


\section{Introduction}

In large parts of the industrialized world, manufacturing employment has been declining. Increased automation of manufacturing production and globalization are thought to be the main causes of this trend. While greater openness to international trade is only one facet of globalization, it is deemed to be the one most closely related to a decline in manufacturing employment in industrialized countries. Turning to a late industrializer, namely Korea, we also find a decline in manufacturing employment. Between 1991 and 2012, manufacturing employment declined from 5.2 million to 4.2 million, while its manufacturing share of employment fell from 28 percent to 17 percent (Source: OECD). Over the same period the merchandise trade to GDP ratio has more than doubled. In this paper, we study the impact of greater trade openness on employment at the firm level in Korean manufacturing. In particular, we examine how firm-level employment is related to trade, primarily input imports.

It needs to be realized at the outset that there could be considerable heterogeneity in how firms react to greater possibilities for input and output trade. For example, these possibilities can provide some firms with the opportunity to import inputs, which could either be substitutes for or complements to inputs produced by workers in-house, depending on which firm level employment could go up or down in response to greater input imports. Also, greater export and import possibilities will benefit the relatively productive firms that will be able to compete with foreign firms in the world market. On the other hand, these greater trading possibilities could hurt the less productive firms who will not be able to survive foreign competition or might in response shrink their output and employment.

To study various possible employment outcomes related to trade, we extend the small-country trade model with heterogeneous firms developed by Demidova and Rodriguez-Clare (2013), itself an extension of the well-known Melitz (2003) model. In the Demidova-Rodriguez-Clare model we incorporate offshoring (imports of inputs), along with final goods trade. As mentioned above, our main focus in this paper is to study the impact of offshoring or importing inputs on firm-level employment. Based on our theory, with an offshoring cost reduction we should expect firms (whether exporting or not) to suffer losses in employment because of the greater effective competition primarily driven by the lower prices charged by each offshoring firm (due to the cost reduction brought about by offshoring). Offshoring, as opposed to non-offshoring, firms experience another effect on their labor 
demand which depends on two elasticity parameters: the elasticity of substitution between inputs and the elasticity of substitution between varieties of output. We call the impact resulting from these two elasticities the substitution-productivity effect and the difference between the two elasticities the net input elasticity of substitution. Our model predicts that when the net input elasticity of substitution is positive a decline in the offshoring cost is associated with a lower firm level employment. In this case, the direct impact of imported inputs substituting for domestic employment dominates the expansion in employment through an increase in final demand brought about by consumers substituting into the final product of such an offshoring firm (away from non-offshoring firms). When the net input elasticity of substitution is negative, the substitution-productivity effect works to increase employment in response to a decrease in offshoring cost. However, this positive employment effect must be balanced against the negative employment effect arising from greater competition, rendering the overall effect ambiguous. Among the offshoring firms, those that export will experience an additional positive exporting effect: a lower cost of production will help expand exports and in turn employment.

Our model also predicts that a decrease in the trading cost of final goods will lead to losses in employment for non-exporting firms. This channel works though a decline in the average industry price, which is equivalent to greater effective competition faced by domestic firms. In addition to such an effect, exporting firms also experience an opposing effect: an increase in their labor demand due to an increase in exports (as exporting costs are now lower).

Our theoretical model acts as a useful guide for empirically investigating the firm-level employment effects of offshoring and final goods trade, especially when it comes to the effects that are heterogeneous across firms. However, there are important aspects of the real world that our theoretical model does not capture, but which might show up in the results of our empirical investigation. Firstly, we do not allow for a pro-competitive effect of offshoring on the market for the importcompeting intermediate input (domestic substitute of the foreign input). When the offshoring cost (trading cost of the offshored input) goes down, a larger fraction of firms would offshore, which could depress the price of the import-competing intermediate input through a fall in its demand. Thus, it is quite possible that there would be a positive productivity effect not only for offshoring firms but also other firms. Secondly, we also take the intrinsic productivity of each firm as given throughout after a firm draws it from a given distribution. The only change we see is in effective 
productivity (a decline in unit cost) that results from greater offshoring due to a fall in the trading cost of the offshored input. There is no other productivity effect of trade in our model, in the form of learning, R\&D etc. There is, however, overwhelming evidence showing a positive productivity effect of import competition which makes firms more efficient. ${ }^{1}$

We perform our empirical investigation using firm-level data from Korea. The firm-level Korean panel data are drawn from the Survey of Business Activity (SBA) for the years 2006-2016. Our empirical work also uses data on trade costs for final goods as well as separately for intermediate goods or inputs. We use effectively applied tariffs from the World Integrated Trade Solution (WITS), which need aggregation and concording to the Korean 2-digit classification. Transport costs are constructed at the 2-digit level by adjusting the US transport costs (for disaggregate categories) for different distances between Korea and its various major trading partners, which is followed by import-weighted aggregation to more aggregate categories, and then a process of concordance. The trade costs are the sum of import tariffs and transport costs. From the final goods trade costs, we create input trade costs using the input-output table for Korea, along with some additional concordance. In addition, for our analysis, we need measures of output and input substitution, which are derived from the elasticities of substitution in Broda and Weinstein (2006), again requiring further aggregation and concording as well as transformation using the input-output matrix. An attractive feature of our firm-level dataset is the presence of data on exports and imports at the firm-level, which we use in our analysis.

Our empirical analysis yields several results, most of them consistent with our theory and/or our economic intuition. To be sure that the impact of trade cost reductions on employment are working through the right channels, we first verify that firm level trading is related to trade costs in the expected direction. We find that input and output trade cost reductions increase both the volume of firm-level exports and imports as well as the probabilities of firms exporting and importing.

Turning to the relationship between employment and trade costs, we find that the correlation between input trade cost and firm employment is positive and statistically significant in the sample of industries with high net input substitutability. The impact is less clear cut for industries with low net input substitutability. This result is consistent with what we find when we interact the net input substitutability with input trade costs using the full sample.

Next we study the relationship between employment and firm level trading activities. Here we 
find, using an IV approach that, on the whole, greater imports have an ambiguous (statistically insignificant) effect on domestic firm-level employment. Consistent with our theoretical predictions, the magnitude of the negative employment effect of input imports is, if any, larger for firms in industries where the net input substitutability is high. Our instrument for imports is the interaction between Chinese exports to its four major partners other than South Korea and the firm's initial share in South Korea's industry-level imports. Given that the initial year of imports used to construct the firm's initial share is not included in the regression sample, these weighted exports are clearly exogenous to Korean firm imports. They also satisfy the exclusion restriction. Our main results are robust to controlling for total factor productivity and imposing alternative restrictions on our sample.

Import status and employment are both ultimately functions of the firm's intrinsic productivity, i.e., larger firms (firms with higher output and employment levels) are the ones that are likely to offshore (import inputs). To address this problem of simultaneity, we use an approach of differencein-differences with propensity score matching, similar to the one used by Girma, Greenaway, and Kneller (2003). Specifically, we use here the machine-learning approach to propensity-score matching by Imbens and Rubin (2015). Across all our difference-in-differences specifications (with propensity score matching) importing (of inputs) leads to higher domestic firm-level employment. As with our other regressions, here as well the employment increasing impact of importing inputs from abroad is greater when the net input elasticity of substitution is lower. And, being an exporter, overall, has a positive effect on employment.

A detailed analytical survey of the literature on the impact of offshoring on various labor-market outcomes is Hummels, Munch and Xiang (2018), from now on HMX. The existing literature on the impact of offshoring on specifically employment is fairly small, and considerable details of those papers are provided in HMX. While one set of papers uses worker-level data, there is another that consists of papers that use employer-employee matched datasets. In the first category, the papers look at how offshoring, measured at the industry level, affects the likelihood of job separations. The papers falling in this category include Egger, Pfaffermayr and Weber (2007) for Austria, Geisheker (2008) for Germany and Munch (2010) for Denmark. The main common result of these three papers is that offshoring reduces the probability of remaining in one's existing job, especially when it is low-skilled. 
In the second category of papers are Hummels, Jorgenson, Munch and Xiang (2014), referred from now on as HJMX, using Danish matched data and Kramarz (2008) using French data. Though their main focus is on wage effects, HJMX, in addition to finding that a doubling of offshoring reduces earnings of low-skilled workers on average by $4.2 \%$, find that a part of this wage reduction is due to "time spent in unemployment." In the case of high-skilled workers, their income loss arising from job loss is more than offset by wage gains. Kramarz, in general, finds a negative relationship between offshoring and employment.

In many ways, the paper closest to ours is the one by Groizard, Ranjan and Rodriguez-Lopez (2015). Using establishment level data from Californian manufacturing industries from 1992 to 2004, they find that, consistent with the prediction of trade models with heterogeneous firms, a decline in trade costs (input as well as output) is associated with job destruction (creation) in the least (most) productive establishments, with firm death most likely in the case of the least productive establishments. Interestingly, the effects of input trade costs on job creation or destruction at the establishment level are greater in magnitude than those of output trade costs. Note that the Groizard et al. paper, unlike ours, does not look at the interaction between importing and exporting or the role of input substitutability or complementarity in the determination of firm-level employment. Also, unlike us, they do not possess information on imports and exports at the firm level and, therefore, are not able to investigate the impact of heterogeneous trade flows at the firm level on firm employment. They are restricted to studying the impact of trade costs, the data on which are at the 3-digit industry level.

The Korean data we use are not employer-employee matched data. They are firm-level data where our variable of interest is firm-level employment. Since our main interest lies in studying the impact of offshoring on firm-level employment, firm-level data are adequate for our purposes. Here we make some advances over the existing literature. First, we not only use industry-level measures of offshoring costs, measured as input trade costs using weights from Korea's input-output table applied to output trade costs, we also go on to use firm-level imports. As argued in HMX, imports by a firm in the manufacturing sector can be viewed as imports of inputs. Such imports of inputs can be a good measure of firm-specific offshoring. To control for the endogeneity or simultaneity of our firm-level offshoring measure, we construct an instrument based on China's exports to other major Asian countries as well the firm's initial share in industry imports. Another innovation in our paper 
is to first theoretically derive the offshoring-employment relationship which changes with the degree of net input substitutability and then investigate the support for this substitution-productivity effect in the data. We also have a set of difference-in-differences regressions using machine learning based propensity score matching. These regressions address the endogeneity of a firm's offshoring status.

The earliest related work which looks at the heterogeneous impact of trade on firm or plantlevel employment is Levinsohn (1999), who finds that in Chile, during their period of trade reforms (1979-86), there were substantial inter-plant differences in the rates of job creation and destruction based on plant size, with the smallest plants three times more likely to destroy jobs through firm death but experiencing smaller magnitudes of job contraction or destruction compared to the largest plants. The latter results are along the lines of the findings of Biscourp and Kramarz (2007), who use French firm-level manufacturing data from 1986 and 1992.

There are empirical studies that, similar to ours, try to separate the effects of input and finalgood trade costs but on other firm-level outcomes. The main outcome variables to have been studied in that literature are plant-level productivity (Amiti and Konings, 2007 and Topolova and Khandelwal, 2011), the range of goods produced at the firm-level (Goldberg, Khandelwal and Pavcnik, 2010), and wages (Amiti and Davis, 2012). There is considerable evidence from these studies that reductions in trade costs, especially in input trade costs, can result in increases in firm/plant productivity and the product variety at the level of the firm. In addition, reductions in input tariffs increase wages in import-using firms (relative to others), while output tariff reductions lower wages in import-competing firms and raise wages in exporting firms. While these outcome variables are quite different, one could easily see how the impact of trade and trade costs on them could constitute additional channels through which employment could be affected.

The remainder of the paper is organized as follows. In the next section we present the theoretical

model. Section 3 discusses the data used in the paper. Section 4 provides empirical results and section 5 provides concluding remarks.

\section{The Model}

We extend the small country trade model of Demidova and Rodriguez-Clare (2013) to incorporate offshoring (along with final goods trade). Here the country of interest is called Home which trades with rest of the world. 


\subsection{Preferences and Demand}

The total size of the workforce in Home is $\mathbb{L}$, which is also the number of individuals in the economy. Individuals' preferences are defined over a number of differentiated, non-numeraire goods and a homogeneous, numeraire good. In particular, the utility function for the representative consumer is given by

$$
\mathbb{U}=H+\sum_{i=1}^{N} \frac{\eta}{\eta-1} Z_{i}^{\frac{\eta-1}{\eta}}
$$

where $H$ denotes the consumption of the homogeneous good, $Z_{i}=\left(\int_{\omega \in \Omega_{i}} z_{i}^{c}(\omega)^{\frac{\sigma_{i}-1}{\sigma_{i}}} d \omega\right)^{\frac{\sigma_{i}}{\sigma_{i}-1}}$ is the CES consumption aggregator of a continuum of differentiated varieties within the $i$ th differentiated goods sector, and $\eta$ is the elasticity of demand for $Z_{i}$ (where $\eta$ governs the substitutability between homogeneous and differentiated goods). Within $Z_{i}, z_{i}^{c}(\omega)$ denotes the consumption of variety $\omega$, $\Omega_{i}$ is the set of differentiated varieties available for purchase, and $\sigma_{i}>1$ is the elasticity of substitution between varieties. We assume that $\sigma_{i}>\eta$ so that differentiated-good varieties (within a differentiated good or sector) are better substitutes for each other than for the homogeneous good.

For differentiated goods, the representative individual's demand for variety $\omega$ of the $i$ th differentiated good sector is given by $z_{i}^{c}(\omega)=\frac{p_{i}(\omega)^{-\sigma_{i}}}{P_{i}^{1-\sigma_{i}}} P_{i} Z_{i}$, where $p_{i}(\omega)$ is the price of variety $\omega$, $P_{i}=\left[\int_{\omega \in \Omega_{i}} p_{i}(\omega)^{1-\sigma_{i}} d \omega\right]^{\frac{1}{1-\sigma_{i}}}$ is the price of the CES aggregator $Z_{i}$, and hence, $P_{i} Z_{i}$ is the household expenditure on differentiated goods produced by sector $i$. Given the quasi-linear and additively separable utility in (1), it follows that $Z_{i}=P_{i}^{-\eta}$, and therefore, the aggregate demand for variety $\omega$ of the $i$ th sector is given by

$$
z_{i}^{d}(\omega)=p_{i}(\omega)^{-\sigma_{i}} P_{i}^{\sigma_{i}-\eta} \mathbb{L}
$$

The homogeneous good, $H$, is produced by perfectly competitive firms using domestic labor only. One unit of domestic labor produces one unit of the homogeneous good. This fixes the domestic wage at 1 as long as some homogeneous good is produced, which we assume to be the case. Therefore, the income of each household simply equals 1 . We assume that the parameters are

such that $\sum_{i=1}^{N} P_{i} Z_{i}=\sum_{i=1}^{N} P_{i}^{1-\eta}<1$ for all $i$, so that a typical individual has enough income to buy all differentiated goods. 
The firms in Home face the following export demand for their products:

$$
z_{i}^{x}(\omega)=A p_{i}^{x}(\omega)^{-\sigma_{i}}
$$

where $p_{i}^{x}$ is the price faced by consumers in the export market. However, there is a fixed cost of exporting, $f_{i}^{x}$, and an iceberg trading cost, which has a general component $\tau_{i}^{x}$ and a firm specific component $t_{x}$. As a result, not all firms will export. Note that the above demand function captures the idea that the income and price index in the rest of the world are taken as given by Home firms.

As in Demidova and Rodriguez-Clare (2013) we assume there is a fixed number of firms producing varieties of the $i$ th good in the rest of the world denoted by $N_{i}^{f}$. Note that this is the implication of the small country assumption, which means the small country, Home is not able to affect the number of firms in the rest of the world and takes that number as given. However, only a subset of firms in the rest of the world will find it worthwhile to export to Home. These exporting firms

from the rest of the world also face a fixed cost of exporting, $f_{i}^{f}$, and an iceberg trading cost, $\tau_{i}^{f}$. As a result, only a subset of these firms are able to export to Home. In the rest of the paper, we are going to make the following symmetry assumption: $\tau_{i}^{x}=\tau_{i}^{f}=\tau_{i}$.

\subsection{Production Structure}

From now on, in order to avoid clutter we drop the subscript $i$ from our notation. In other words, we are focusing on firms in a given differentiated goods sector (out of several of them). Suppose that after incurring an entry cost of $f_{E}$ a firm draws a triplet $\psi=\left(\varphi, t_{x}, t_{o}\right)$ where $\varphi$ is the exogenous productivity of the firm, $t_{x} \in\left[1, \overline{t_{x}}\right]$ is the firm-specific component of the variable cost of exporting, and $t_{o} \in\left[1, \overline{t_{o}}\right]$ is the firm specific component of the variable cost of offshoring. $\psi$ is drawn from a distribution $G(\psi)$ with the p.d.f. $g(\psi)$. The production function of a Home firm with triplet $\psi$ and whose productivity is $\varphi$ is $z(\psi)=\varphi Y(\psi)$, with

$$
Y(\psi)=\left[\alpha L(\psi)^{\frac{\rho-1}{\rho}}+(1-\alpha) M(\psi)^{\frac{\rho-1}{\rho}}\right]^{\frac{\rho}{\rho-1}}
$$

where $L(\psi)$ is a composite of inputs produced within the firm, $M(\psi)$ is a composite of inputs procured from outside the firm, and $\rho \geq 0$ is the elasticity of substitution between the two types of inputs. $^{2}$ We assume that one unit of labor is required to produce one unit of $L(\psi)$. 
The composite input $M(\psi)$ can be either procured domestically or it can be offshored. Let $p_{s}(\psi)$ denote the price paid by a firm with offshoring status $s$ for a unit of composite input $M(\psi)$, for $s \in\{n, o\}$, where $n$ denotes "not offshoring" and $o$ denotes "offshoring". If $M(\psi)$ is procured domestically, then $p_{n}(\psi)=p_{n}$ for all $\psi$, that is, we are implicitly assuming that $p_{n}$ units of the numeraire good translate into one unit of input $M(\psi)$. If the production of $M(\psi)$ is offshored, a firm has to pay a fixed cost of offshoring, $f_{o}$, and a variable cost, $p_{o}(\psi)$, per unit of input $M(\psi)$. Let $p_{M}^{*}$ denote the price of input $M$ in the foreign country, and let $\lambda>1$ denote the iceberg cost of offshoring common to all firms and recall that $t_{o}$ is the firm specific variable cost of offshoring. It follows that

$$
p_{o}(\psi)=\lambda t_{o} p_{M}^{*}
$$

so that a decline in $\lambda$ makes offshoring more attractive. Note that domestic firms have incentives to offshore only if $p_{o}(\psi)<p_{n}(\psi)=p_{n}$.

Given our production function and (3), the marginal cost of a firm with triplet $\psi$ and offshoring status $s$ is given by $\frac{c_{s}(\psi)}{\varphi}$, where

$$
c_{s}(\psi) \equiv\left[\alpha^{\rho}+(1-\alpha)^{\rho} p_{s}(\psi)^{1-\rho}\right]^{\frac{1}{1-\rho}}
$$

is the price of a unit of $Y(\psi)$ for a firm with status $s \in\{n, o\}$. Whenever a firm offshores it must be the case that $p_{o}(\psi)<p_{n}$, therefore, $c_{o}(\psi)<c_{n}(\psi)=c_{n}$ as well.

There is a fixed cost of operation, $f$, for every producing firm. In addition to offshoring, firms can export as well. There is a fixed cost of exporting $f_{x}$, an iceberg shipping cost of final goods, with a component common to all firms, given by $\tau>1$, and a firm specific component, $t_{x}$ mentioned earlier, so that the overall variable shipping cost is $\tau t_{x}$. Note that the general component of the variable shipping cost is symmetric (equal) for exports and imports of final goods, so that a reduction in $\tau$ would imply a reduction in this cost in both directions.

\subsection{Equilibrium}

With CES preferences, the price set by a Home firm with productivity $\varphi$ in the home market is

$$
p(\psi)=\left(\frac{\sigma}{\sigma-1}\right) \frac{c_{s}(\psi)}{\varphi}, \text { for } s \in\{n, o\}
$$


The price that a firm charges in the foreign market, if it exports, is given as follows.

$$
p^{x}(\psi)=\left(\frac{\sigma}{\sigma-1}\right) \frac{\tau t_{x} c_{s}(\psi)}{\varphi}, \text { for } s \in\{n, o\}
$$

Given the above description of the model, there are 4 possible types of firms: Those which sell only domestically and do not offshore, those which export but do not offshore, those which offshore but do not export and those which do both offshoring and exporting.

A firm with triple $\left(\varphi, t_{x}, t_{o}\right)$ chooses the mode that maximizes its net profit. The net profit is given by

$$
\pi(\psi ; \tau, \lambda)=\left(\left(\frac{\sigma}{\sigma-1}\right) \frac{c_{s}(\psi)}{\varphi}\right)^{1-\sigma}\left(\frac{P^{\sigma-\eta} \mathbb{L}+\left(\tau t_{x}\right)^{1-\sigma} A I_{x}}{\sigma}\right)-f-f_{o} I_{o}-f_{x} I_{x}
$$

where $I_{o}$ is the indicator variable for an offshoring firm and $I_{x}$ is the indicator variable for an exporting firm.

Denote the productivity of the marginal surviving firm by $\widehat{\varphi}$. If this firm doesn't export or offshore then

$$
\left(\left(\frac{\sigma}{\sigma-1}\right) \frac{c_{n}}{\widehat{\varphi}}\right)^{1-\sigma} \frac{P^{\sigma-\eta} \mathbb{L}}{\sigma}-f=0
$$

The above gives the value of $\widehat{\varphi}$ for given $P$. It is shown in the appendix that the sufficient conditions for the marginal surviving firm to neither export nor offshore are

$$
\left(\left(\frac{\left.c_{o}(\psi)\right|_{t_{o}=1}}{c_{n}}\right)^{1-\sigma}-1\right) f<f_{o} ;\left(\left(\frac{\sigma}{\sigma-1}\right) \frac{\left.c_{o}(\psi)\right|_{t_{o}=1}}{\widehat{\varphi}}\right)^{1-\sigma}\left(\frac{\tau^{1-\sigma} A}{\sigma}\right)<f_{x} .
$$

The former requires the offshoring fixed cost to be high relative to the fixed cost of operation $f$ while the latter requires the fixed cost of exporting to be high relative to the size of the Foreign market captured by $A$. The term $\left.c_{o}(\psi)\right|_{t_{o}=1}$ refers to the cost of producing input $Y$ for an offshoring firm with the lowest possible variable offshoring cost.

Next, substituting out $P^{\sigma-\eta}$ in (8) using (9), the net profits can be written as

$$
\pi(\psi, \widehat{\varphi} ; \tau, \lambda)=\left(\frac{\widehat{\varphi} c_{s}(\psi)}{\varphi c_{n}}\right)^{1-\sigma} f+\left(\left(\frac{\sigma}{\sigma-1}\right) \frac{c_{s}(\psi)}{\varphi}\right)^{1-\sigma}\left(\frac{\left(\tau t_{x}\right)^{1-\sigma} A}{\sigma}\right) I_{x}-f-f_{o} I_{o}-f_{x} I_{x}
$$

That is, profits are a function of $\widehat{\varphi}$ and triple $\psi$. Therefore, if we know $\widehat{\varphi}$ we can determine the 
profits of each firm and also whether they offshore and/or export.

$\widehat{\varphi}$ is determined by the free entry condition

$$
\Pi \equiv \int_{\widehat{\varphi}}^{\infty} \int_{t_{o}} \int_{t_{x}} \pi(\psi, \widehat{\varphi} ; \tau, \lambda) g(\psi) d t_{x} d t_{o} d \varphi=f_{e}
$$

In the above $\psi$ is the triplet $\left(\varphi, t_{x}, t_{o}\right), t_{o}$ denotes $t_{o} \in\left[1, \overline{t_{o}}\right]$ and $t_{x}$ denotes $t_{x} \in\left[1, \overline{t_{x}}\right]$. The proof of existence is given in the appendix. Once we have $\widehat{\varphi}$ then $P$ is obtained by (9). The mass of domestic and foreign firms can be determined by noting that the price index $P_{i}=\left[M_{d} \int_{\psi} p_{d}(\psi)^{1-\sigma_{i}} d G(\psi)+M_{f} \int_{\varphi} p_{f}(\varphi)^{1-\sigma_{i}} d F(\varphi)\right]^{\frac{1}{1-\sigma_{i}}}$ where $M_{f}$ is the mass of foreign exporters exporting to the home market and $F(\varphi)$ is the distribution function of the productivity of these exporters, $M_{d}$ is the mass of domestic firms. $M_{f}$ is going to be a subset of the mass of foreign firms, $N_{i}^{f}$. Since the masses of domestic and foreign firms are not going to be crucial for the analysis below, we ignore this aspect of the theoretical model.

Once we have $\widehat{\varphi}$, we can determine the mode of globalization of each firm given its $\psi$. A firm chooses the mode that maximizes its net profits from the alternatives listed in (10). In general, among active firms, those with low $t_{x}$ are more likely to export, while those with low $t_{o}$ are more likely to offshore. As well, higher productivity firms are more likely to engage in offshoring and exporting due to the fixed costs associated with these activities.

Next, we derive the following lemma (proof in appendix) which is useful in comparative statics below.

Lemma: $\frac{d \widehat{\varphi}}{d \tau}<0 ; \frac{d \widehat{\varphi}}{d \lambda}<0$.

That is, decreases in the costs of trading final goods or offshoring both increase the survival productivity cutoff. The result with respect to $\tau$ is, what has been called in some parts of the literature, the "selection effect" in the Melitz model and its various extensions, and the result with respect to $\lambda$ is its analog for offshoring. Intuitively, a decrease in the cost of offshoring reduces the cost of production of offshoring firms. Thus there is a reduction in the sectoral price index $P$, which in turn has a profit reducing effect. As a result the break-even firm (which is purely domestic both in sales and input use) will be one with a higher productivity. 


\subsection{Trading costs and firm level trade: empirical implications}

While our main interest in the paper lies in studying the impact of trading on employment, since we have rich data on firm level trading activities, we first derive some implications on the relationship between trade costs and firm level trade. This will be useful in indicating to us whether or not any employment changes due to trade cost changes we see are through changes in firm-level trade and firm's trading status. It is shown in the appendix that a decrease in the output trading cost, $\tau$, increases exports at both the intensive and extensive margins. That is, existing exporting firms export more and more firms are likely to export. Similarly, a decrease in the input trading cost $\lambda$ also increases exports by making firms more competitive in the export market. It also increases the probability of a firm exporting.

Looking at firm level imports, it is shown in the appendix that a decrease in the input trading cost, $\lambda$, has both direct and indirect effects on firm level imports. The indirect effect operates through changes in $\widehat{\varphi}$ which works to reduce imports, however, the direct effect increases imports at both the intensive and extensive margins. A decrease in the output trading cost, $\tau$, also affects imports. It affects the imports of exporting firms because if exports expand these firms need more inputs, including imported inputs, to service export demand. In addition, a decrease in $\tau$ affects all firms indirectly through an increase in $\widehat{\varphi}$. That is, a decrease in $\tau$ would indirectly reduce firm level imports.

\subsection{Trading costs and employment: some empirical implications}

Since our main aim is in deriving the implications of changes in the costs of offshoring and trading final goods on employment, we present the expressions for employment derived in the appendix. Denoting the employment for domestic production by $L_{s}^{d}(\psi)$, for exports by $L_{s}^{x}(\psi)$, and total employment by $L_{s}(\psi)$, we obtain

$$
L_{s}(\psi)=L_{s}^{d}(\psi)+I_{x} L_{s}^{x}(\psi)
$$

where $I_{x}$ is an identity function which takes the value 1 if the firm exports, and zero otherwise and

$L_{s}^{d}(\psi)=\alpha^{\rho}(\sigma-1) c_{s}(\psi)^{\rho-\sigma}\left(\frac{\varphi c_{n}}{\widehat{\varphi}}\right)^{\sigma-1} f ; L_{s}^{x}(\psi)=\alpha^{\rho}\left(\frac{\sigma-1}{\sigma}\right)^{\sigma} c_{s}(\psi)^{\rho-\sigma}\left(\tau t_{x}\right)^{1-\sigma} \varphi^{\sigma-1} A$, for $s \in\{n, o\}$

Denote the labor demand for the 4 possible types of firms by $L_{n d}(\psi), L_{n x}(\psi), L_{o d}(\psi)$, and $L_{o x}(\psi)$, 
where $n d$ denotes no offshore, no export, $n x$ denotes no offshore, export, od denotes offshore, no export, and finally ox denotes offshore, export.

\subsubsection{Output trading cost, $\tau$, and employment}

Using (12) derive the following expressions for the change in labor demand resulting from a change in the output trading cost.

$$
\begin{aligned}
& \frac{d \ln \left(L_{n d}(\psi)\right)}{d \tau}=-\frac{(\sigma-1)}{\widehat{\varphi}} \frac{d \widehat{\varphi}}{d \tau}=\frac{d \ln \left(L_{o d}(\psi)\right)}{d \tau} ; \\
& \frac{d \ln \left(L_{n x}(\psi)\right)}{d \tau}=-\epsilon_{d} \frac{(\sigma-1)}{\widehat{\varphi}} \frac{d \widehat{\varphi}}{d \tau}-\left(1-\epsilon_{d}\right) \frac{(\sigma-1)}{\tau}=\frac{d \ln \left(L_{o x}(\psi)\right)}{d \tau} .
\end{aligned}
$$

where $\epsilon_{d}$ is the share of labor used for domestic production. Since $\frac{d \widehat{\varphi}}{d \tau}<0$, we expect $\frac{d \ln \left(L_{n d}(\psi)\right)}{d \tau}=$ $\frac{d \ln \left(L_{o d}(\psi)\right)}{d \tau}>0$. That is, non-exporting firms experience a decrease in employment following a decrease in output trading cost. The signs of $\frac{d \ln \left(L_{n x}(\psi)\right)}{d \tau}$ and $\frac{d \ln \left(L_{o x}(\psi)\right)}{d \tau}$ are ambiguous which means that the impact on exporting firms is ambiguous because an increase in exports expands employment as captured by the second term but an increase in domestic competition reduces employment as captured by the first term.

Thus, we can use the following estimating equation to capture the impact of the output trade cost on labor demand of the different types of firms.

$$
\ln \left(L_{i j t}\right)=\widetilde{\beta}_{0}+\widetilde{\beta}_{1} \tau_{j t}+\widetilde{\beta}_{2} \tau_{j t} E X P_{i j t}+\widetilde{\beta}_{3} \tau_{j t} E X P_{i j t} I M P_{i j t}
$$

where $E X P$ captures the export status of the firm and $I M P$ captures the import or offshoring status. Verify from above that

$$
\frac{d \ln \left(L_{i j t}\right)}{d \tau_{j t}}=\widetilde{\beta}_{1}+\widetilde{\beta}_{2} E X P_{i j t}+\widetilde{\beta}_{3} E X P_{i j t} I M P_{i j t}
$$

Therefore, we expect $\widetilde{\beta}_{1}>0$ and $\widetilde{\beta}_{2}<0 . \widetilde{\beta}_{3}$ can be positive or negative because the impact of $\tau$ on exporting firms that offshore vs those who do not offshore differs just by $\epsilon_{d}$ which is the share of labor going to meet domestic production. There is no clear prediction on how these should be vary according to the offshoring status of exporting firms. 


\subsubsection{Input trading cost, $\lambda$, and employment}

Using the same steps as above, derive the following expressions for the change in labor demand resulting from a change in offshoring cost.

$$
\begin{aligned}
& \frac{d \ln \left(L_{n d}(\psi)\right)}{d \lambda}=-\frac{(\sigma-1)}{\widehat{\varphi}} \frac{d \widehat{\varphi}}{d \lambda}>0 ; \frac{d \ln \left(L_{n x}(\psi)\right)}{d \lambda}=-\epsilon_{d}\left[\frac{(\sigma-1)}{\widehat{\varphi}} \frac{d \widehat{\varphi}}{d \lambda}\right]>0 ; \\
& \frac{d \ln \left(L_{o d}(\psi)\right)}{d \lambda}=-\frac{(\sigma-1)}{\widehat{\varphi}} \frac{d \widehat{\varphi}}{d \lambda}+(\rho-\sigma) \frac{d \ln \left(c_{o}(\psi)\right)}{d \lambda} ; \frac{d \ln \left(L_{o x}(\psi)\right)}{d \lambda}=-\epsilon_{d} \frac{(\sigma-1)}{\widehat{\varphi}} \frac{d \widehat{\varphi}}{d \lambda}+(\rho-\sigma) \frac{d \ln \left(c_{o}(\psi)\right)}{d \lambda}
\end{aligned}
$$

The first two inequalities follow from the fact that $\frac{d \widehat{\varphi}}{d \lambda}<0$. That is, non-offshoring firms, whether they export or not, experience a decrease in labor demand as the offshoring cost decreases. For offshoring firms, we have two terms. They also experience a decrease in labor demand due to the first

term because $\frac{d \widehat{\varphi}}{d \lambda}<0$. The second term, however, has an ambiguous sign. Recall that $\frac{d \ln \left(c_{o}(\psi)\right)}{d \lambda}>0$. Therefore, the sign of the second term is same as the sign of $(\rho-\sigma)$.

The second term in the expression above captures two effects. First, a decrease in $\lambda$ implies that offshoring firms find offshored inputs to be cheaper, and hence they further substitute offshored inputs for domestic labor which leads to a decrease in the demand for domestic labor. The strength of this effect depends on $\rho$, the elasticity of substitution between domestic labor and offshored inputs. The larger the $\rho$ the stronger this effect. We can call this the substitution effect of offshoring. Second, since offshoring firms become more productive (their marginal cost of production decreases), the demand for their products increases. This leads to an increase in labor demand. The strength of this latter effect depends on the elasticity of demand for the firm (same as the elasticity of substitution between varieties, $\sigma$ ). We can call this the productivity effect of offshoring. The net substitutionproductivity effect depends on $\rho-\sigma$. If $\rho>\sigma$, then the substitution effect dominates and hence a decrease in the cost of offshoring reduces the demand for labor through the substitution-productivity effect, while if $\rho<\sigma$, then the substitution-productivity effect leads to an increase in the demand for labor. In the remainder of the paper we refer to $\rho-\sigma$ as the parameter capturing the net input substitutability.

The above can be captured by the following estimating equation:

$$
\ln \left(L_{i j t}\right)=\beta_{0}+\beta_{1} \lambda_{j t}+\beta_{2} \lambda_{j t} E X P_{i j t}+\beta_{3} \lambda_{j t} E X P_{i j t} I M P_{i j t}+\beta_{4} \lambda_{j t}\left(\rho_{j}-\sigma_{j}\right) I M P_{i j t}+\varepsilon_{i j t} .
$$


The triple interaction term, $\lambda_{j t} E X P_{i j t} I M P_{i j t}$ arises from the fact that $\epsilon_{d}$ of an offshoring firm that exports is different from that of a non-offshoring firm that exports. The above yields

$$
\frac{d \ln \left(L_{i j t}\right)}{d \lambda_{j t}}=\beta_{1}+\beta_{2} E X P_{i j t}+\beta_{3} E X P_{i j t} I M P_{i j t}+\beta_{4}\left(\rho_{j}-\sigma_{j}\right) I M P_{i j t}
$$

Since $\frac{d \ln \left(L_{n d}(\psi)\right)}{d \lambda}>0$, we expect $\beta_{1}>0$. That is, purely domestic firms suffer an employment loss from a reduction in offshoring cost. The share of labor in domestic production, $\epsilon_{d}<1$, therefore, $\beta_{2}<0$ such that $\beta_{1}+\beta_{2}>0$ and $\beta_{1}+\beta_{2}<\beta_{1}$. That is, an exporting firm that does not offshore also suffers an employment loss, but the impact is smaller because its export market is unaffected. For offshoring firms the existence of the substitution-productivity effect implies $\beta_{4}>0$. However, they are subject to increased competition in the domestic market captured by the $\frac{d \widehat{\varphi}}{d \lambda}$ term but the offshoring firms that export experience a smaller percentage impact because their export markets are unaffected. So, $\beta_{1}+\beta_{2}+\beta_{3}$ is smaller than $\beta_{1}$ and $\beta_{1}+\beta_{2}+\beta_{3}>0$. Therefore, it must be the case that $\beta_{2}+\beta_{3}<0$. Whether $\beta_{3}$ is positive or negative is not clear because whether $\epsilon_{d}$ is larger for exporting firms that offshore or exporting firms that do not offshore is not clear.

Note that the above estimating equation requires an industry level estimate of the net input substitution parameter: $\left(\rho_{j}-\sigma_{j}\right)$. We have reliable estimates of $\sigma_{j}$ but our constructed measure of $\rho_{j}$ has some weaknesses, and therefore, we also try an alternate estimation where we assume $\rho_{j}$ to be the same across industries. In that case the estimating equation becomes

$$
\ln \left(L_{i j t}\right)=\beta_{0}+\beta_{1} \lambda_{j t}+\beta_{2} \lambda_{j t} E X P_{i j t}+\beta_{3} \lambda_{j t} E X P_{i j t} I M P_{i j t}+\beta_{4} \lambda_{j t}\left(-\sigma_{j}\right) I M P_{i j t}+\beta_{5} \lambda_{j t} I M P_{i j t}+\varepsilon_{i j t} .
$$

where $\beta_{5}$ absorbs the effect of $\rho_{j}$.

Since our offshoring cost measures are at the industry level and we have access to the firm level trade data, we also estimate the impact of importing directly on employment. The underlying assumption is that imports are going to respond to changes in offshoring cost. In this case our estimating equation is the following.

$$
\ln \left(L_{i j t}\right)=\beta_{0}+\beta_{1} \text { import }+\beta_{2} \text { import } * E X P_{i j t}+\beta_{3}\left(\rho_{j}-\sigma_{j}\right) \text { import }_{i j t}+\varepsilon_{i j t} .
$$

Of particular interest here is the sign of $\beta_{3}$ which we expect to be negative. That is, increased 
imports should reduce employment in industries $\rho_{j}-\sigma_{j}>0$ due to the substitution-productivity effect and the opposite should be true when $\rho_{j}-\sigma_{j}<0$.

\section{Data Description}

\subsection{Firm-level Variables}

The firm-level Korean panel data are drawn from the Survey of Business Activity (SBA) for the years 2006-2016. Conducted by Statistics Korea, this survey covers all business entities with a capital stock greater than US\$300,000 and employment greater than 50 regular workers. Restricting our sample to the manufacturing sector, our sample consists of 9,504 firms and 63,529 observations. Our firm-level imports, exports, sales, capital stock and employment data come from the SBA.

\subsection{Trade Cost}

The sectoral trade cost is an important determinant of offshoring, imports and exports. Since only the two-digit Korean Standard Industrial Classification (KSIC, revision 9) code is provided to us for each firm by Statistics Korea to preserve confidentiality, to match with our firm-level data, the trade cost is also constructed at the two-digit level of the KSIC, revision 9. The specifics of the construction of the output and input trade costs are provided in the following subsections.

\subsubsection{Output Trade Cost}

We use the standard definition of output trade cost in the literature, which is the sum of the tariff and transport cost as a percentage of the value of imports. The import weighted sectoral tariff is arrived at by constructing an import-weighted average of all the six-digit HS level Effectively Applied (AHS) import tariffs from the World Bank's World Integrated Trade Solution (WITS) within each two-digit industry. We then use our own concordance table between HS and KSIC to construct the first part of the output trade costs at the KSIC two-digit level.

Since transport cost information between Korea and each of its partners is not available, we use as proxies the distance-adjusted transformations of the U.S. costs of shipping from all the same trading partners. ${ }^{3}$ The product level ad valorem transport cost can be defined as the ratio of import charge to the customs import value, where import charge is the cost of all freight, insurance and 
other charges in the process of export. The customs import value is the total value of imports at the border excluding duties and import charges. ${ }^{4}$ Bernard, Jensen, and Schott (2006) calculated U.S. sectoral transport cost using the same data source. They found the import weighted average for the entire manufacturing sector to be $5.6 \%$ during the period $1977-81,4.4 \%$ during $1982-86$, and 4.1\% during 1987-1991. Our simple average for the Korean case for the manufacturing sector for the period 2006-2010 turns out to be $2.6 \%$, while the import-weighted average is $1.8 \%$. Considering that our data are more recent and given Korea's proximity to China, we should expect this smaller average.

\subsubsection{Input Trade Cost}

Following Amiti and Konnings (2007), input trade cost (ITC) is generated by taking the weighted average of the output trade cost $(O T C)$ with the weights from the Korean input-output table for the year 2005. The calculation of ITC is as follows.

$$
I T C_{k t}=\sum_{j} O T C_{j t} \cdot s_{k j}
$$

where $s_{k j}$ are cost shares of industry $j$ in the production of a good in industry $k$ in the year 2005 . One empirical hurdle using this method is that the computed input trade cost is highly correlated with the output trade cost, with correlation coefficient being 0.86 for year 2016 and 0.79 overall. This makes it difficult to separately identify the impact of the input and output trade costs when both trade costs are simultaneously included in the same regression. For this reason, we also construct an alternative input trade cost (ITC2) measure by excluding diagonal elements of the input-output table from our computations. We use ITC2 when we jointly estimate impacts of both input and output trade costs. The correlation coefficient between the output trade cost and the alternative input trade cost measure is much lower, 0.76 for year 2016 and 0.66 overall.

\subsubsection{Output and Input Elasticities of Substitution}

As shown in the above theory sections, the net input substitutability $(\rho-\sigma)$ significantly affects the overall effect of offshoring on firm level domestic labor demand. The data on output elasticity of substitution are from Broda and Weinstein (2006) and are the estimates of the elasticity of substitution between product varieties (within each product category) for Korea specifically during 
the period 1990-2001. ${ }^{5}$ This output elasticity of substitution estimate for each product (SITC rev.3) is first converted to HS code (6 digit) and is then assigned to KSIC industries using a concordance table we have created. Then using the level of imports as weights, our two-digit industry level output elasticity of substitution measure $\left(\sigma_{j}\right)$ for each industry $j$ is created. Finally, the input elasticity of substitution measure $\left(\rho_{k}\right)$ is obtained by using input-output tables in the same way these weights were used for constructing the input trade cost.

$$
\rho_{k}=\sum_{j} \sigma_{j} \cdot s_{k j}
$$

Here is a possible justification for our measure of input elasticity of substitution. Let's, for the purpose of a simple example, suppose that different varieties of aluminum and steel are all the inputs used in producing a particular final product. The output elasticity of substitution for steel measures the degree of substitutability between different varieties of steel, while, similarly, the output elasticity of substitution for aluminum measures the degree of substitutability between different varieties of aluminum. As the input share of aluminum gets closer to zero (or, alternatively, to one), the input elasticity of substitution, measuring the substitutability between all the different varieties of inputs used in this product would converge to the output elasticity of substitution for steel (or, alternatively, for aluminum). The input-output coefficients will give us the relative importance of steel and aluminum in the production of this final output, and we, accordingly, use those weights to get a weighted-average measure of the input elasticity of substitution. Since some varieties of inputs will be produced in-house and some outside (and we are not making any assumptions on the differences in the characteristics of the two kinds of inputs), we believe the average elasticity of substitution between input varieties will capture the elasticity of substitution between in-house inputs and other inputs. However, we acknowledge that this is a highly imperfect measure of the input elasticity of substitution. But, then, this is the best we can do with the available data. Nevertheless, we perform a robustness check to compensate for the imperfect nature of our measure.

Table 1 provides all the summary statistics of the main variables used in this paper. 


\section{Empirical Results}

While our main interest in the paper lies in studying the relationship of trade and trade costs with employment, we begin our empirical exercise by looking at the relationship between trade costs and firm level trade since, using our access to firm-level trade, we want to confirm that the impacts of changes in trade costs on employment are indeed taking place through changes in firm-level trade flows.

\subsection{Relationship between trade costs and firm level trade}

We first look at the impact of trade costs on firm exports. As discussed in the theoretical section, our model predicts that a decrease in $\tau$ or $\lambda$ increases exports at both the intensive and extensive margins. The regression specification used to test this theoretical prediction is as follows:

$$
\ln (1+\text { exports })_{i j t}=\beta_{0}+\beta_{1} I T C_{j t}+\beta_{2} O T C_{j t}+\Gamma \mathbb{Z}_{i j t}+\varepsilon_{i j t}
$$

$\ln (1+\text { exports })_{i j t}$ represents the logarithm of exports of firm $i$ in industry $j$ in the year $t$. Adding 1 to the value of exports allows us to keep observations with zero exports as well. $I T C_{j t}$ denotes input trade cost (our measure of $\lambda$ ), OTC $C_{j t}$ denotes output trade cost (our measure of $\tau$ ), and $\mathbb{Z}_{i j t}$ is a vector of control variables, which - depending on the specification - includes either two-digit industry fixed effects or firm fixed effects. Year fixed effects are always included in all of our regressions.

Table 2 shows the impact of industry level trade costs on firm level exports. In panel A, we present results including two-digit industry fixed effects, which exploit the within-industry variation in the data. By contrast, in panel $\mathrm{B}$, we focus on the within-firm variation by including firm fixed

effects. The robust standard errors are clustered at the industry by year level. While OTC denotes output trade cost (our measure of $\tau$ ), ITC denotes input trade cost (our measure of $\lambda$ ). In columns (1) and (2) of both panels, we see a negative and significant impact of input and output trade costs, respectively, on the intensive margin of exports. Results with firm and year fixed effects indicate that a one percentage point reduction in the input trade cost (which is on average more than a 10 percent reduction) leads to a 5.4 percent increase in the intensive margin of exports (in firm-level exports), while a one percentage point reduction in the output trade cost (which is again on average more than a 10 percent trade cost reduction) leads to a 2.7 percent increase in the intensive margin 
of exports.

At the level of disaggregation at which we are performing our study and at which the inputoutput table for Korea is constructed, the diagonal elements of the input-output table are relatively large in magnitude. In other words, the input of an industry into itself is large, which results, as mentioned before, in a very high correlation between the input and output tariffs, in turn making it difficult to identify their effects separately when thrown into the right-hand side of a regression simultaneously. Therefore, as mentioned earlier, we construct a modified input trade cost variable based on the off-diagonal elements of the input-output matrix applied to industry-level output trade costs. This is the input trade cost measure, denoted by ITC2 used in all our regressions in which both input and output trade costs are thrown in simultaneously. Column (3) shows the results of such a regression, where both input trade cost and output trade cost are estimated simultaneously. Here, results in panel B show that a one percentage point decrease (on average a 10 percent decrease) in the input trade cost leads to a 8.8 percent increase in the intensive export margin.

From columns (4) through (6), where we look at the extensive margin using the same set of specifications again, but where the dependent variable is a $0-1$ variable indicating whether the firm is exporting or not, we see that the impact of a percentage point decrease in the input trade cost is to increase the probability of exporting by $0.005-0.017$, while a percentage point decrease in the output trade cost also leads to an increase in this probability by 0.001-0.014. Thus, we can conclude from the results presented in Table 2 that input and output trade cost reductions increase both the volume of exports of exporting firms as well as the probability of firms exporting. ${ }^{6}$

We next turn our attention to the impact of trading costs on firm level imports. As discussed in the theoretical section, a decrease in the trading cost (both input and output trading cost) has a direct positive effect on imports but there is an indirect negative effect rendering the theoretical impact ambiguous. Table 3 reports results of the impact of trading costs on firm level imports. The estimating equation is same as in (17) except that the dependent variable is imports instead of exports. Once again, all columns in Table 3 show results from regressions with the same set of specifications and fixed effects as in Table 2. Again, robust standard errors are clustered at the industry-by-year level. In columns (1) and (2), we see a negative and significant impact of input and output trade costs respectively on the intensive margin of imports. In panel $\mathrm{B}$, a one percentage point reduction in the input trade cost (more than a 10 percent reduction) leads to a 5.5 percent 
increase in the intensive margin of imports (in firm-level imports of inputs), while a one percentage point reduction in the output trade cost (again on average more than a 10 percent reduction) leads to a 3.5 percent increase in the intensive margin of imports.

Column (3) shows the results of a regression where our modified input trade cost (ITC2) and the output trade cost variables are thrown in simultaneously into the right-hand side. Again, focusing on panel B, a one percentage point decrease (on average a 10 percent decrease) in the input trade cost leads to a 5 percent increase in the intensive import margin. A one percentage point decrease in the output trade cost leads to a 2.2 percent increase in the intensive import margin. From columns (4) through (6), where we look at the extensive margin using all three models, we see that the impact

of a percentage point decrease in the input trade cost is to increase the probability of importing by 0.005-0.020, while a percentage point decrease in the output trade cost leads to an increase in the probability of importing by $0.003-0.007$. Therefore, the results in Table 3 show that the impact of a decrease in the trading cost (both input and output trading cost) is to increase imports both at the intensive and extensive margins. Empirically, the direct effect seems to outweigh the countervailing indirect effect of a decrease in trading costs on firm level imports.

While some of the results on the impact of trading costs on firm level trade may be obvious, it is worth highlighting the link between exports and imports. We found evidence that a decrease in the input trading cost increases exports by making firms more competitive in the export market. Similarly, a reduction in the output trading cost increases imports because a boost to firm exports gives a boost to their demand for imported inputs as well.

Now we turn our attention to the relationship between employment and trading costs.

\subsection{Relationship between trade costs and employment}

\section{Split-sample analysis}

To empirically study the relationship between trade costs and firm employment, we first try the following simple specification:

$$
\ln (\text { employment })_{i j t}=\beta_{0}+\beta_{1} T C_{j t}+\Gamma \mathbb{Z}_{i t}+\varepsilon_{i j t}
$$

where $\ln (\text { employment })_{i j t}$ is the $(\log )$ employment for firm $i$ in industry $j$ in year $t, T C_{j t}$ represents 
either the output or input trade cost defined as above, $\mathbb{Z}_{i j t}$ includes firm and year fixed effects. Recall from the theoretical section that the impact of the input trade cost on employment depends crucially on the substitution-productivity effect which we capture empirically through the net input substitutability, $\rho-\sigma$. Our theoretical model predicts that due to the substitution-productivity effect a decrease in the input trade cost, $\lambda$, is likely to reduce employment if $\rho-\sigma>0$ but the impact is ambiguous in the opposite case. ${ }^{7}$ To capture the impact of net input substitutability $(\rho-\sigma)$ in this simple framework, we split the sample into a high net substitutability group and a low net substitutability group. We do these splits in two ways: on the basis of $\rho-\sigma$, and, alternatively, based solely on the degree of output substitutability $(\sigma)$. The latter alternative partitioning is done since the input substitutability measure $(\rho)$ is imperfect and can be questioned. If we assume an average $\rho$ for all firms, then effectively we can perform our partitioning based on $\sigma$ alone.

We use here the Broda-Weinstein elasticity of substitution. Theory predicts a decline in the input trade cost to reduce firm-employment in the high $\rho-\sigma$ or low $\sigma$ industries and an ambiguous effect in the low $\rho-\sigma$ or high $\sigma$ industries. That is, we expect $\beta_{1}>0$ in the former industries but the sign of the comparative static capturing $\beta_{1}$ is ambiguous for the latter industries.

The results are presented in Table 4. Panel A provides results for the split based on the sign of $(\rho-\sigma)$. In Panel B we split them based on $\sigma$ alone and whether $\sigma$ is above the mean or below the mean. Since the distribution of $\sigma$ is highly skewed with most observations lying in the group of $\sigma$ below the mean, panel $\mathrm{C}$ provides an alternative split where industries are grouped according to whether $\sigma$ is above the median or below the median. All these regressions include firm and year fixed effects and robust standard errors are clustered at the industry-by-year level. Columns 1 and 2 in all three panels use ITC as the measure of input trade cost. Consistent with our theory, the coefficient of ITC (estimate of $\beta_{1}$ ) is positive and statistically significant in column 1 (when the net substitutability is high) in all panels. In column 2 (when the net substitutability is low), the sign of the estimate of $\beta_{1}$ is negative in panels $\mathrm{A}$ and $\mathrm{B}$, and positive in panel $\mathrm{C}$, but statistically insignificant in all three cases. The coefficient estimates in column 1 imply that for a one percentage point decline in the input trade cost (which is more than a 10 percent reduction), employment decreases by 0.7 $1.3 \%$ when the net input substitutability is high. Columns 3 and 4 in all panels of table 4 use $O T C$ instead of $I T C$ and the results are less clear cut with $O T C$, particularly in panels B and C. ${ }^{8}$ Finally, columns 5 and 6 show the results when ITC2 (our modified input trade cost measure) and 
OTC are thrown in simultaneously, as was done earlier while studying the relationship between firm level trade and trade costs. Here we obtain the result that the coefficient of ITC2 is positive and significant in all panels when the net input substitutability is high (in column (5)). In the low net input substitutability case (column (6)), the sign is negative in all panels and the coefficient is statistically significant in Panels A and C.

Intuitively, as the input trade costs fall and the imported inputs become cheaper, if the imported inputs are substitutes of in-house inputs (produced using domestic labor), then this fall in the price of foreign inputs results in a decrease in firm employment, through a substitution away from inhouse inputs. However, output substitutability means that there will be an increase in employment driven by increased output demand for offshoring firms resulting from a fall in input trade costs and the consequent lower output price. Thus, if input substitutability dominates output substitutability, then this fall in input trade costs results in a decrease in firm employment. If the imported inputs are net complements to in-house labor (input substitutability is dominated by output substitutability), then a fall in input trade costs causes an increase in the firm-level demand for domestic labor.

\section{Full-sample analysis}

We next estimate the following grand specification which is directly derived from the theory (see equations (13) and (14)) using our entire manufacturing sample.

$$
\begin{aligned}
\ln (\text { employment })_{i j t}= & \beta_{0}+\beta_{1} I T C_{j t}+\beta_{2} I T C_{j t} \times E X P_{i j t}+\beta_{3} I T C_{j t} \times E X P_{i j t} \times I M P_{i j t}(19) \\
& +\beta_{4}\left(\rho_{j}-\sigma_{j}\right) I T C_{j t} \times I M P_{i j t}+\tilde{\beta}_{1} O T C_{j t}+\tilde{\beta}_{2} O T C_{j t} \times E X P_{i j t} \\
& +\tilde{\beta}_{3} O T C_{j t} \times E X P_{i j t} \times I M P_{i j t}+\Gamma \mathbb{Z}_{i j t}+\varepsilon_{i j t}
\end{aligned}
$$

The dependent variable, (log) employment, as well as the left-hand side variables, input and output trade cost are defined the same as before, $I M P_{i j t}\left(E X P_{i j t}\right)$ equals one if firm $i$ is an importer (exporter) of industry $j$ in year $t$ (and zero otherwise), $\mathbb{Z}_{i j t}$ contains either industry or firm fixed effects depending on the specification, year fixed effects (always included) and the intercept $I M P_{i j t}$ and $E X P_{i j t}$ dummies.

From our theory, we would expect $\beta_{1}>0, \beta_{2}<0$ and $\beta_{1}+\beta_{2}>0, \beta_{1}+\beta_{2}+\beta_{3}>0$ and

$\beta_{2}+\beta_{3}<0$, and finally $\beta_{4}>0$. Similarly, we expect $\tilde{\beta}_{1}>0, \tilde{\beta}_{2}<0$ and $\tilde{\beta}_{3}$ can be positive or 
negative. The reasons behind those predictions have been carefully discussed in the theory section. Let us quickly recall why we expect $\beta_{4}>0$. When it is cheaper to import inputs, in the case of high net input substitutability, we will get a reduction in firm employment. The direct employment lost due to offshoring more than offsets the scale effect from overall cost reduction (productivity increase).

We present results for regressions with industry fixed effects in the first 4 columns and regressions with firm fixed effects in the last 4 columns of Table 5. Again, robust standard errors are clustered at the industry-by-year level. Also, columns (1), (2), (5) and (6) use only input trade cost while columns (3) and (7) use only output trade cost. Columns (4) and (8) include both input and output trade costs and provide estimates of the grand specification in equation (19). The coefficient on the input trade cost stays positive in all specifications, and becomes statistically significant when we focus on within-firm employment changes. The coefficient on the triple interaction term for input trade cost $((\rho-\sigma) \times I T C \times I M P)$ is positive and statistically significant throughout all regressions and is not affected much by the inclusion of the other interaction terms. That is, we get strong support for the theoretical prediction that $\beta_{4}>0$. Clearly, as shown by the level (own) term of ITC and the coefficient of interaction $I T C \times E X P$, non-offshoring firms $(I M P=0)$ always experience an employment reduction as a result of an input trade cost reduction, which is also consistent with our theoretical prediction. The results with output trading cost, OTC, are less clear cut. However, in the regressions with firm fixed effect in columns (7) and (8), the coefficient of $O T C$ is positive and significant while the interactions are mostly insignificant suggesting that a decrease in output trading cost is associated with lower employment.

Focusing on input trading costs and the results with firm fixed effects in columns (5) to (8), the results are in line with our theory's predictions. Recall that our theory predicted $\beta_{1}>0, \beta_{2}<0$ and $\beta_{1}+\beta_{2}>0, \beta_{1}+\beta_{2}+\beta_{3}>0$ and $\beta_{2}+\beta_{3}<0$, and finally $\beta_{4}>0$. Looking at column (8), the estimates of $\beta_{i}$ are consistent with all of these predictions. The estimate of $\beta_{1}$ is .005 , the estimate of $\beta_{2}$ is -.002 , the estimate of $\beta_{3}$ is 0 , and the estimate of $\beta_{4}$ is .002 . These estimates are statistically significant except for the estimate of $\beta_{3}$.

Based on the estimates in column (8) we can also say the following for the 4 different types of firms: (i) a decrease in offshoring cost reduces the employment of firms that neither offshore nor export (coefficient of ITC $=.005$ ); (ii) a decrease in offshoring cost reduces the employment of firms 
that export but do not offshore (sum of coefficients of ITC and ITC*EXP $=.003$ ) but the impact is smaller than for non-trading firms; and, (iii) for offshoring firms that do not export the impact is given by the sum of coefficients of ITC and ITC* $(\rho-\sigma) * I M P=.005+(\rho-\sigma) .002$ which is positive if $(\rho-\sigma)>-2.5$ and negative otherwise. That is, in industries where $(\rho-\sigma)>-2.5$ a decrease in offshoring cost reduces employment while in industries where $(\rho-\sigma)<-2.5$ a decrease in offshoring cost increases employment. There are only 3 industries (covering $3.3 \%$ of firms in our sample) with $(\rho-\sigma)<-2.5$, so we can say that in most industries a decrease in the input trading cost is associated with a decrease in firm employment. iv) Finally, for firms that offshore and export, the impact of a decrease in the offshoring cost is given by the sum of coefficients ITC, + $I T C *(\rho-\sigma) * I M P, I T C * E X P$, and ITC *EXP*IMP $=.003+(\rho-\sigma) .002$. That is, in industries where $(\rho-\sigma)>-1.5$ a decrease in offshoring cost reduces employment, while in industries where $(\rho-\sigma)<-1.5$, a decrease in offshoring cost increases employment. There are 4 industries (covering $9.2 \%$ of firms in our sample) with $(\rho-\sigma)<-1.5$. Note that both IMP and EXP dummies have positive signs throughout. This shows that, under frictionless trade $(I T C=0, O T C=0)$, both importing and exporting firms have higher employment than totally domestic firms (that neither import nor export). This is also true for trade under frictions when $\rho \geq \sigma$. The firm fixed-effect model has an advantage over the model with industry fixed effects in that it controls for any timeinvariant, firm-specific confounders.

Since our measure of $\rho$ is imperfect, to reassure ourselves and the readers, we run a specification where we assume a common input elasticity of substitution across all industries. In this case, in our regression $(\rho-\sigma) \times I M P \times I T C$ gets replaced by the combination of $I M P \times I T C$ and $(-\sigma) \times I M P \times I T C$ since $\rho$ is a constant. The results with this robustness check are shown in Table 9 in our appendix. The results are qualitatively similar.

To sum up, a decrease in input trade costs on average reduces firm employment, however, the relationship is weaker the lower the net input substitutability (low $(\rho-\sigma)$ or high $\sigma$ ) suggesting that the substitution-productivity effect plays an important role in moderating or magnifying the negative effect of imports on firm employment.

Since our trade cost measures are at the industry level and we have access to firm level data on imports, below we directly study the relationship between imports and employment. 


\subsection{Relationship between firm level trade and employment}

As pointed by Hummels et al. (2018), firm-level importing data show large differences in offshoring activity across firms and thus, compared to the IO table, provide greater scope for the identification of the effects of offshoring on labor-market outcomes. Recall that in our theoretical model we have firm level trade costs as well, and firm level trade data captures the impact of firm level trading costs which could not be captured using the industry level trade costs in the results provided earlier.

Based on the estimating equation (16) derived in the theoretical section, we run the following specification.

$\ln (\text { Employment })_{i j t}=\beta_{0}+\beta_{1} \ln (1+\text { imports })_{i t}+\beta_{2} \ln (1+\text { imports })_{i t} E X P_{i j t}+\beta_{3} \ln (1+\text { imports })_{i t}\left(\rho_{j}-\sigma_{j}\right)+\Gamma \mathbb{Z}_{i j t}+\varepsilon_{i j t}$

Depending on the specification we ran, $\mathbb{Z}_{i j t}$ includes year fixed effects, export dummies $\left(E X P_{i j t}\right)$, and - depending on our specification - either industry or firm fixed effects. Since we are using log of imports as the regressor, to include all firms (importing and non-importing), we add 1 to the value of imports, and hence we use $\ln (1+$ imports $)$ as the key regressor of interest.

$\beta_{1}$ captures the relationship between imports (offshoring) and employment for non-exporting firms in the industry where the substitution-productivity effect roughly equals zero $\left(\rho_{j} \approx \sigma_{j}\right)$. $\beta_{1}+\beta_{2}$ captures the same relationship for exporting firms. Of particular interest here is the sign of $\beta_{3}$ which we expect to be negative as discussed in the theory section. That is, increased imports should be associated with lower employment in industries where $\rho_{j}-\sigma_{j}>0$ due to the substitution-productivity effect and the opposite should be true when $\rho_{j}-\sigma_{j}<0$.

Clearly, the relationship between imports and employment suffers from an endogeneity problem. While we are interested in seeing how a change in imports induced by a change in the trading cost affects employment, there are other factors such as a firm specific productivity shock or demand shock which could simultaneously raise both employment and imports without a change in the trading cost. We will address this endogeneity problem using an instrumental variable approach, which we describe in the next few paragraphs.

We need to look at the part of a firm's imports that are exogenous and are not driven by any firmlevel shocks, that also directly impact the firm's employment. We construct an instrument using Chinese exports in different industries to other major economies in Asia interacting with individual 
firm's initial share of industry imports. We use China's exports to Japan, India, Vietnam, and Taiwan to construct our industry-level, Chinese productivity-driven export shocks. ${ }^{9}$ These four top Asian importers of Chinese products together have import structure similar to Korea's. Hence, our instrument delivers accurate first-stage predictions. We have run robustness checks by further restricting the country set to either only Japan or expanding it by including other trading partners such as Malaysia and Indonesia, and our results stay robust.

Since China's exports to Korea have risen rapidly (and Korea is China's 4th largest exporting destination as of 2017) and intermediate goods make up a large share of China's exported products, using China's exports to construct our instrument for intermediate input is appropriate and relevant in our case. The firm-level instrument is defined as follows:

$$
\ln M I V_{i t}=\ln \left(\frac{M_{i 0}}{M_{j 0}} \times \text { Exports }_{j t}^{\text {China } \rightarrow \text { Other }}\right)
$$

$\frac{M_{i 0}}{M_{j 0}}$ is the firm $i$ 's import share in industry $j$ at the beginning of the period, Exports ${ }_{j t}^{\text {China } \rightarrow \text { Other }}$ represents China's exports to other economies in industry $j$ in year $t$. This measure captures China's export supply shocks as in Autor et al. (2013) and Acemoglu et al. (2016).

The idea is that if Chinese exports to these other countries expand in these industries, the common element in this growth as well as the growth in the imports by the Korean firms we study is driven by Chinese productivity growth, which is similar to the effect of a lower trade cost. Therefore, from the point of view of Korean firms, this can be viewed as the availability of cheaper inputs. In the terminology of our theoretical model, it would be a lowering of $p_{M}^{*}$, the price of the imported input. As Figure 1 shows, there is a strong positive correlation between Chinese exports and the firm level imports in Korea. The first stage results shown in Table 7 (corresponding to second-stages shown in the 2SLS regressions reported in Table 6.) are strong, as the Cragg-Donald Weak IV F-stat is above the Stock-Yogo critical value by a wide margin. The instrument also satisfies the exclusion restriction because Chinese exports to other Asian countries should not affect Korean firm level employment through any channel other than the imports of these firms from China.

Note that our instrument is created by using import weights $\frac{M_{i 0}}{M_{j 0}}$ from the initial year of imports. Since many firms have zero imports in the initial years, if we were to simply use initial year imports as weights the instruments for these firms will always have a value of zero even for years when 
they have positive imports. We use two alternative approaches to deal with this problem. First, we include firms only from a year after they start importing, with weights constructed using the first year of their imports. We follow HJMX in doing this and hence we call the sample created by this approach the HJMX sample. Note that this approach involves throwing a lot of data for firms in years when their import is zero. Therefore, we create an alternate sample, that we call the gap-year sample, where the instrument takes the value zero as long as the firm's import is zero, and then if the import becomes positive in year $t$, we drop the firm in year $t$ and instrument its imports from year $t+1$ onwards, using the import weight (share) based on year $t$. The reason the year $t$ observation is dropped is to make sure that our constructed instruments remain truly out of sample. Note that the first year of imports (used to construct import shares for our instrument) is also thrown out of the HJMX sample.

The results from both the OLS and 2SLS regressions for both the HJMX sample and the gap year sample are presented in Table 6. Panel A presents the results with industry fixed effects and panel B with firm fixed effects and robust standard errors are clustered at the firm level. Let us first discuss the OLS results presented in columns (1), (3), (5), and (7). Note from the results in columns (1) and (5) in both panels that greater imports are associated with greater employment. More interestingly, the coefficient of $\ln (1+$ imports $) \times\left(\rho_{j}-\sigma_{j}\right)$ is negative and significant, which is consistent with the substitution-productivity effect. In columns (3) and (7) we control for firm productivity using log of total factor productivity and the results are qualitatively similar. Controlling for firm productivity partially alleviates the endogeneity problem because a firm specific productivity shock could increase both imports and employment.

Focusing on the HJMX sample and the regressions with firm fixed effect in column (3) of panel $\mathrm{B}$, we note that even though $\ln (1+$ imports $) \times\left(\rho_{j}-\sigma_{j}\right)$ has a negative coefficient, the largest value of $\rho_{j}-\sigma_{j}$ in our sample is 3.75 and therefore, greater importing is associated with greater employment for all industries and the effect is smaller for industries with high $\rho_{j}-\sigma_{j}$. The effect is stronger for offshoring firms that export as well as suggested by the positive coefficient of $\ln (1+$ imports $) * E X P$. The EXP dummy surprisingly has a negative coefficient in columns 1-4 of Panel A.

Finally, we turn to the instrumental variable results. We report results for the 2-stage-leastsquare (2SLS) regressions in columns (2), (4), (6) and (8). The results with industry and year fixed effects are in panel A and with firm and year fixed effects are in Panel B. In Panel A, for all the 
2SLS regressions the coefficient of $\ln (1+$ imports $)$ is positive and significant, while the coefficient of $\ln (1+$ imports $) \times\left(\rho_{j}-\sigma_{j}\right)$ is negative and significant, as predicted by theory. In panel $\mathrm{B}$, since we have firm fixed effects (and year fixed effects), we effectively control for firm-specific time-invariant variables, and so there is much less of an omitted variable bias, if any, in this case. The point estimate for the coefficient for $\ln (1+$ imports $)$ is negative in columns (2), (4), (6) and (8) in panel B (i.e., in both HJMX and gap samples) but lacks statistical significance, as opposed to being positive and significant in the corresponding OLS regressions in columns (1), (3), (5) and (7). The coefficient of $\ln (1+$ imports $) \times\left(\rho_{j}-\sigma_{j}\right)$ remains negative and statistically significant in the 2SLS regressions (like in the OLS regressions). The partial derivative of $\ln ($ employment) with respect to $\ln (1+$ imports $)$ for non-exporting firms is $\beta_{1}+\beta_{3}\left(\rho_{j}-\sigma_{j}\right)$. Using results from columns (4) and (8) gives us negative values of this partial derivative throughout when actual values of $\left(\rho_{j}-\sigma_{j}\right)$ from our sample are plugged in (except when $\left(\rho_{j}-\sigma_{j}\right)=-23.66$, the lowest value in our sample, using the coefficients in column (8)). However, using the delta method to calculate the standard errors of the estimates of the partial derivative at different values of $\left(\rho_{j}-\sigma_{j}\right)$ shows us that all the negative partial derivative estimates are statistically insignificant. ${ }^{10}$ Looking at the confidence interval of the estimates of these partial derivatives, we find that they are more likely to be negative, but positive estimates cannot be ruled out. For example, using column (4), which uses the HJMX sample, the $95 \%$ confidence interval for this partial derivative at the 50 th percentile value of $\left(\rho_{j}-\sigma_{j}\right)(=.05)$ is $[-0.3,0.08]$. The $95 \%$ confidence intervals are also very similar and close for other values of $\left(\rho_{j}-\sigma_{j}\right)$ except for $\left(\rho_{j}-\sigma_{j}\right)=-23.66$.

The coefficient of $\ln (1+$ imports $) * E X P$ is positive and mostly significant in the 2SLS regressions, suggesting that greater imports result in lower employment reductions (or higher employment increases) for exporting firms, which is consistent with our theoretical prediction. The positive effect of exporting reduces the magnitude of the negative estimate of the partial derivative of employment with respect to imports. For the HJMX sample, the partial effect remains negative and statistically insignificant for exporting firms. For the gap sample (column 8), however, the partial derivatives of employment with respect to imports for exporting firms are positive and, for many values of $\left(\rho_{j}-\sigma_{j}\right)$, highly significant. In particular, the partial derivatives are larger the lower the value of net input substitutability $\left(=\rho_{j}-\sigma_{j}\right)$.

To sum up, our regressions using the variation in trade costs across industries reported in 
Table 5 suggest that lower trade costs are associated with lower employment. Using firm-level data on imports we find from the OLS regressions in Table 6 that greater imports are associated with greater employment, however, our 2SLS regressions with firm fixed effects yield an uncertain (ambiguous) association between imports and employment, as the estimates of the partial derivative of employment with respect to imports, though negative (especially for non-exporting firms), are statistically insignificant in most cases. One consistent pattern across all regressions in Tables 5 and 6 is the evidence for the presence of the substitution-productivity effect. That is, in industries with low net input substitutability $\left(\right.$ small $\left(\rho_{j}-\sigma_{j}\right)$ ) either a decrease in the offshoring cost (in Table 5) or an increase in importing (in Table 6) is associated with a smaller employment reduction (or a larger employment increase), while in industries with high net input substitutability (large $\left.\left(\rho_{j}-\sigma_{j}\right)\right)$ we get a larger employment reducing (smaller employment increasing) effect of such changes in offshoring costs or importing.

Also, given that our measure of $\rho$ is imperfect, as with Table 5, we perform a robustness exercise where we assume $\rho$ to be constant across industries and allow only $\sigma$ to vary in which case the term $\ln (1+\text { imports })_{i t}\left(\rho_{j}-\sigma_{j}\right)$ is replaced by $\ln (1+\text { imports })_{i t}\left(-\sigma_{j}\right)$ and $\ln (1+\text { imports })_{i t}$ since $\rho$ is treated as a constant. Since $\ln (1+\text { imports })_{i t}$ is already included as a regressor, our estimating equation (20) becomes

$\ln (\text { Employment })_{i j t}=\beta_{0}+\beta_{1} \ln (1+\text { imports })_{i t}+\beta_{2} \ln (1+\text { imports })_{i t} E X P_{i j t}+\beta_{3} \ln (1+i m p o r t s)_{i t}\left(-\sigma_{j}\right)+\Gamma \mathbb{Z}_{i j t}+\varepsilon_{i j t}$

The results from estimating the above equation are presented in Table 11 in the appendix and the results are qualitatively similar to those in Table 6.

Our final empirical exercise involves studying the impact of a change in the status of a firm from non-importing to importing on employment.

\subsection{Results from the difference-in-differences estimation with propensity score matching}

While the instrumental variable approach adopted in the previous section worked well for how changes in imports are associated with changes in employment, in this section we study how importing is associated with employment. That is, how does a change in import status affect employment? 
A problem with a simple comparison of the levels of employment of importing and non-importing firms is that the import status itself is endogenous. A firm specific productivity or demand shock could lead to both a change in a firm's import status and employment. Alternatively, larger firms may be more likely to import given the fixed cost of importing, and therefore, the causality may run from firm size or employment to importing. Ideally if a firm starts importing in year $t$ we would like to compare its employment in year $t+s$ where $s \geq 0$ with its employment in year $t+s$ if the firm were not importing in $t+s$. Since we cannot know what the firm's employment in year $t+s$ would have been if it was not importing, we construct a counterfactual using propensity score matching. Our method here is similar to the one used by Girma, Greenaway, and Kneller (2003). Since the focus of our paper is on offshoring or importing of inputs, we abstract here from the endogeneity of the exporting status.

First, we restrict the target sample to firms that are observed for the entire sample period, 2006-2016. Then, we define an import starter as a firm that became an importer during the period 2007-2016. The treatment group here consists of these firms, since our focus in this paper is on importing of inputs (or offshoring). If a firm stops importing a few years after it starts importing, we include that firm only in its importing years. In order for it to be included, in our treatment group, a firm must import for 3 continuous years. Our control group consists of firms that did not import at all over our full 11-year sample period. Matching of firms in the treatment group with those in the control group was performed on a cross-section by cross-section (year by year) basis. That is, for each year (during the period 2007-2016), the following probit model is estimated.

$\mathbb{P}\left(\right.$ Import Starter $\left._{i t}=1\right)=\operatorname{Prob}\left(\ln \left(\right.\right.$ TFP $\left._{i, t-1}\right), \ln \left(\right.$ Sales $_{i, t-1}, \ln \left(\right.$ TotalAsset $\left._{i, t-1},(\text { Sales } / \text { WageBill })_{i, t-1}\right)$

We adopted the latest machine learning matching technique by Imbens and Rubin (2015) to create better balanced treatment and control groups, given our rigid restriction on the sample. The Imbens-Rubin matching method we use can be summarized as follows. We start the matching procedure based on a set of basic covariates: TFP, Sales, Total Assets, and Sales to Wage Bill Ratio, all in one-year lagged format. We then examine the contribution of other firm-level variables, including each, one at a time, by calculating the Likelihood-Ratio statistic for the null hypothesis that the newly included covariate has a zero coefficient. If at least one of the LR test statistics 
is greater than the set critical value, we add the covariate with the largest LR statistic. ${ }^{11}$ We stop when no variable's LR statistic exceeds the critical value. We start the examination with all linear terms, and then expand our search among all interaction and quadratic terms of the selected covariates to further improve the matching quality.

For each year for which we run the probit for propensity score matching, our sample for the probit regression consists of firms that start importing that year and those that do not import at all that year. For each import starting firm that year, a firm from the control group that is the closest in terms of the probability of starting importing that year is selected. After matched firms are identified for each year, all observations on matched firms across all years are pooled to create our final matched sample panel dataset.

To make sure our matching has been successful we perform a test of balancing hypothesis, which consists of t-tests of equality of means of the matching variables between the control and treatment groups. We also checked that for the matching variables the standardized bias, mean difference between treatment and control group adjusted by the square root of average sample variance, was small enough after matching. A rule of thumb is that it should ideally be less than $5 \%$ (in absolute value) after matching (Caliendo and Kopeinig, 2008).

We present the results for the matching performance in our propensity score matching in Table 8. We see that, for the initial year, the standardized bias prior to matching was very high - in the range of $5.1 \%$ to $118 \%$. After matching this bias goes down to $-0.1 \%$ to $5.4 \%$. While before matching we could easily reject the null hypothesis that the mean of each variable in the treatment group is the same as that in the control group except for TFP, after matching we cannot reject this null for any of the variables except for TFP. ${ }^{12}$ The test of balancing results before and after matching for main covariates are presented in Table 8 and Figure 2.

To find out the impact of importing on the firm's total employment, a difference-in-differences regression was run on the matched panel dataset as per the following estimating equation.

$$
\ln (\text { employment })_{i t}=\beta_{0}+\beta_{1} I M P_{i, t}+\varepsilon_{i t}
$$

where $I M P_{i, t}$ is a dummy variable which for firm $i$ takes the value 1 if it is importing in year $t$ (and is 0 otherwise). Given the way our matched data set has been created, this variable takes the value 0 for a treatment firm until it starts importing, and from then on the variable takes the value 
1 indicating the post import starting periods for firms in the treatment group. For firms in the control group, this variable takes the value 0 throughout.

Similar to equation (20) which was based on the theoretical model, we also run the following regression.

$$
\ln (\text { employment })_{i t}=\beta_{0}+\beta_{1} I M P_{i, t}+\beta_{2} I M P_{i, t} E X P_{i t}+\beta_{3}\left(\rho_{j}-\sigma_{j}\right) I M P_{i, t}+\Gamma \mathbb{Z}_{i t}+\varepsilon_{i t}
$$

Table 9 presents results of the regression equation (23) and (24) where robust standard errors are clustered at the firm level. The first 3 columns use only the year fixed effect. To control for firm specific and time invariant unobservables that may be affecting employment, we use firm fixed effects in the last 3 columns. It is clear from columns (1) and (4) that importing firms on average have higher employment compared to their non-importing controls. The results in columns (2) and (5) suggest that the positive relationship between importing and employment is weaker for firms in industries where $\left(\rho_{j}-\sigma_{j}\right)$ is positive or where the substitution-productivity effect is strong. However, even for the industry with highest $\left(\rho_{j}-\sigma_{j}\right)$, the overall effect of importing on employment is positive. In columns (3) and (6) we also include $I M P * E X P$ interaction to allow the impact of importing to be different for exporting firms. This interaction is positive and significant in the OLS in column (3) but becomes insignificant in column (6). Focusing on the specification in column (6) note that a firm that becomes an importer experiences an increase in employment but the effect is smaller the larger the industry $\left(\rho_{j}-\sigma_{j}\right)$. For the industry with the highest $\left(\rho_{j}-\sigma_{j}\right)(=3.75)$, an increase in importing leads to an increase in employment of $0.74 \%$ while in the industry with the lowest $\left(\rho_{j}-\sigma_{j}\right)(=-23.66)$, it leads to an increase in employment of $7 \%$. For importing firms that export, the effect is slightly larger.

Since our measure of $\rho$ is imperfect, we run, as we did earlier for the regressions in Tables 5 and 6 , a specification where we assume a common input elasticity of substitution across all industries. In this case, in our regression $I M P \times(\rho-\sigma)$ gets replaced by the combination of $I M P$ and $I M P \times(-\sigma)$ since $\rho$ is a constant. Since $I M P$ is already included, effectively, we just replace $I M P \times(\rho-\sigma)$ with $I M P \times(-\sigma)$. The results are qualitatively similar and are provided in Table 12 in the appendix.

Thus, we find from our difference-in-differences estimation that, on average, when firms switch from non-importing to importing, their employment increases. This effect is stronger when the net input substitutability is low (low $\rho-\sigma$ ). Exporting also has a positive effect on employment. 
In panel B of table 6 , in the 2SLS case the importing-employment relationship was statistically insignificant and, therefore, unresolved. However, in the PSM case importing status and employment are unambiguously positively associated. It is important to note that the results in Table 6 for the HJMX sample capture the intensive margin effect of importing on employment, the results in Table 9 capture the extensive margin effect. While it is possible that when a firm switches from nonimporting to importing its employment increases as captured in Table 9, but a marginal increase in imports for an existing importer may not lead to clear-cut effects in one direction or the other. Thus, we do not see any contradictions between those results.

\section{Conclusions}

In this paper, we extend the small country trade model with firm heterogeneity, developed by Demidova and Rodriguez-Clare (2013), where we incorporate offshoring (along with final goods trade). Our theoretical model acts as a useful guide for empirically investigating the firm-level employment effects of input and final goods trade, especially when it comes to the effects that are heterogeneous across firms.

We perform our empirical investigation using firm-level data from Korea for the years 20062016, and data on trade costs for final goods as well as separately for intermediate goods or inputs, combining data from different sources and transforming, aggregating and concording according to our needs, specific to the country we study, namely Korea. There was also similar effort involved in the creation of our measures of input and output substitution.

Our empirical analysis yields several results, most of them fairly consistent with our theory. As expected from theory, the correlation between input trade cost and firm employment is positive and statistically significant in the sample of industries with high net input substitutability. The impact is less clear cut for industries with low net input substitutability.

We find from our OLS regressions that greater imports are associated with greater employment. However, our 2SLS regressions, that include both firm and year fixed effects, yield an uncertain (ambiguous) association between imports and employment, as the estimate of the partial derivative of employment with respect to imports is statistically insignificant in many cases. One consistent pattern across all regressions is the evidence for the presence of the substitution-productivity effect. That is, in industries with greater net input substitutability we get a larger employment reducing 
(smaller employment increasing) effect of such changes in offshoring costs or importing while in industries with a smaller net input substitutability either a decrease in the offshoring cost or an increase in importing is associated with a smaller employment reduction (or a larger employment increase).

We use the approach of difference-in-differences with machine-learning based propensity score matching to address the simultaneity of imports, import status and employment. Across all our difference-in-differences specifications (with propensity score matching) importing (of inputs), on average, leads to higher domestic firm-level employment (relative to not importing). Moreover, consistent again with our theorized substitution-productivity effect, here the employment increasing impact of importing inputs from abroad is greater when the net input substitutability is low.

\section{Acknowledgements}

We thank Bill Horrace, Yoonseok Lee, and Mary Lovely for comments on an earlier version. We also thank participants at the Rocky Mountain Empirical Trade conference, 2017, especially the discussant Federico Esposito, as well as participants at the Western Economic Association meeting, 2017, especially the discussant Bo-Young Choi, and seminar participants at Jadavpur University. The standard disclaimer applies.

\section{Notes}

${ }^{1}$ See for instance Harrison (1994), Krishna and Mitra (1998), Pavcnik (2002), Amiti and Konings (2007), Topalova and Khandelwal (2010) etc.

${ }^{2} \rho$, like some of the other parameters such as $\sigma$, can vary across the various differentiated goods sectors.

${ }^{3}$ The data on industry transport costs are based on product-country-level transport costs which are available from "U.S. Imports of Merchandise" (obtained from Peter Schott's webpage). Collected by the US census bureau, this dataset contains direct transport cost information for each product from various countries of origin to the US. To use the U.S. transport cost data for the construction of Korean transport costs, we perform the following steps. First, we construct Korea's transport cost at the HS 6-digit level with each of its trading partners, using as proxies the distanceadjusted transformations of the U.S. costs of shipping from the same countries. However, for these transformations to result in valid proxies it is important to make sure that the US import structure is close to Korea's, which we actually find to be the case. For example, there is a 98 percent overlap between the products imported by Korea and the US from China, while in the case of imports from the EU this overlap is 94 percent. There is also very significant overlap in products imported from other parts of the world. Finally, industry-level import-weighted transport costs 
are computed after averaging product level costs weighted by imports. When we compute weights to be applied to product-level transport costs of imports from the EU, we use the total amount of imports from all EU27 member countries. Similarly, the imports from all three NAFTA countries are used as weights for arriving at Korea-US transport costs.

${ }^{4}$ Conventionally, matched partner c.i.f. to f.o.b. ratio from UN COMTRADE database is used as a commodity level transport cost measure. However, as Hummels and Lugovskyy (2006) pointed out, this indirect transport cost measure is not usable at the commodity level due to severe measurement error. They found only $10 \%$ of the ad valorem shipping costs (at the 2-digit level) to be in the $0-100 \%$ range.

${ }^{5}$ The estimates are publicly available at David Weinstein's website.

${ }^{6}$ Note that we have assumed symmetry (both in our model as well as our empirical analysis) in the output trade costs across exports and imports. That is, the same output trade cost is faced by both Korean exporters and firms exporting to Korea. The first part of the justification for this assumption is that an important component of our measure of trade cost is transport cost. Transport costs are really symmetric even empirically, so a reduction in them either over time within the same industry or as we move from one industry to another over time will mean that the costs of both importing competing products as well as of exporting go down. The second part of the justification rests on the reciprocity of tariff reductions arising from negotiations at the WTO.

${ }^{7}$ Strictly speaking, in our model the substitution-productivity effect applies only to offshoring firms (firms that import inputs). However, in practice, non-offshoring firms can also be similarly affected through the competitive pressure of the trade cost decline on the market for domestically produced intermediate inputs (produced outside the final goods firm).

${ }^{8}$ Recall that we do not have a theoretical prediction for how employment should vary with output trade costs across industries with different $\rho-\sigma$. Our theoretical predictions hold for input trade costs alone. Since a large part of the inputs is produced within a sector as seen in the large diagonal elements of the input-output matrix, the output trade costs might be capturing some of the input cost effects. That is why we ran regressions using output costs as well.

${ }^{9}$ Note that China's industry level exports are being used here, which may not be exactly what firms in those respective industries in other countries import. However, at the two-digit industry level, most of the inputs come from the same industry. As mentioned above, the diagonal elements of any input-output table, at this level of aggregation, are fairly large. Besides, our instrumental variable is arrived at by interacting with a firm's initial share in industry-level imports.

${ }^{10}$ Again, at $\left(\rho_{j}-\sigma_{j}\right)=-23.66$, the partial derivative based on the coefficients estimated in column (8) is positive and statistically significant.

${ }^{11}$ The critical value used for criterion $\left(C_{L}\right)$ is usually around 2.71 .

${ }^{12}$ The difference in TFP between the treatment group and the control group was not very different even before matching with a p-value of .056. In the matched sample, this p-value doesn't change much and is at .049. 


\section{References}

[1] Amiti, M., and D. R. Davis (2012): "Trade, Firms, and Wages: Theory and Evidence", Review of Economic Studies, 79(1), 1-36.

[2] Amiti, M., and J. Konings (2007): “Trade Liberalization, Intermediate Inputs, and Productivity : Evidence from Indonesia," American Economic Review, 97(5), 1611-1638.

[3] Bernard, A. B., J. B. Jensen, and P. K. Schott (2006): "Trade Costs, Firms and Productivity," Journal of Monetary Economics, 53, 917-937.

[4] Biscourp, P., and F. Kramarz (2007): "Employment, Skill Structure and International Trade: Firm-Level Evidence for France." Journal of International Economics, 72(1), 22-51.

[5] Broda, C., and D. E. Weinstein (2006): "Globalization and the Gains from Variety," The Quarterly Journal of Economics, 121(2), 541-585.

[6] Caliendo, M., and S. Kopeinig (2008): "Some Practical Guidance for the Implementation of Propensity Score Matching," Journal of Economic Surveys, 22(1), 31-72.

[7] Demidova, S., and A. Rodriguez-Clare (2013): "The Simple Analytics of the Melitz Model in a Small Economy," Journal of International Economics, 90(2), 266-272.

[8] Egger, P., M. Pfaffermayr, and Andrea Weber (2007): "Sectoral Adjustment of Employment to Shifts in Outsourcing and Trade: Evidence from a Dynamic Fixed Effects Multinomial Logit Model," Journal of Applied Econometrics 22(3): 559-580.

[9] Feenstra, R. C., J. Romalis, and P. K. Schott (2002): "U.S. Imports, Exports, and Tariff Data, 1989-2001," NBER Working Papers 9387, National Bureau of Economic Research, Inc.

[10] Geisheker, I. (2008): "The Impact of International Outsourcing on Individual Employment Security: A Micro-Level Analysis," Labour Economics 15(3), 291-314.

[11] Girma, S., D. Greenaway, and R. Kneller (2003): "Export Market Exit and Performance Dynamics: A Causality Analysis of Matched Firms," Economics Letters, 80, 181-187. 
[12] Goldberg, P. K., A. K. Khandelwal, N. Pavcnik, and P. Topalova (2010): "Imported Intermediate Inputs and Domestic Product Growth : Evidence from India," Quarterly Journal of Economics, 125(4), 1727-1767.

[13] Groizard, J.L., P. Ranjan, and A. Rodriguez-Lopez (2015): "Trade Costs and Job Flows: Evidence from Establishment-Level Data," Economic Inquiry, 53(1), 173-204.

[14] Hummels, D., and V. Lugovskyy (2006): "Are Matched Partner Trade Statistics a Usable Measure of Transportation Costs?," Review of International Economics, 14(1), 69-86.

[15] Hummels, D., J.B. Munch, and C. Xiang (2018): "Offshoring and Labor Markets," Journal of Economic Literature 56(3), 981-1028.

[16] Hummels, D. R. Jorgenson, J.R. Munch, and C. Xiang (2014): "The Wage Effects of Offshoring: Evidence from Danish Matched Worker-Firm Data," American Economic Review 104(6), 15971629.

[17] Imbens, G.W., and D.B. Rubin (2015): Causal inference in statistics, social, and biomedical sciences, Cambridge University Press, New York.

[18] Kramarz, F. (2008): "Offshoring, Wages and Employment: Evidence from Data Matching Imports, Firms and, Workers," unpublished.

[19] Levinsohn, J. (1999): "Employment Responses to International Liberalization in Chile," Journal of International Economics , 47(2), 321-344.

[20] Melitz, M. J. (2003): "The Impact of Trade on Intra-Industry Reallocations and Aggregate Industry Productivity," Econometrica, 71(6), 1695-1725.

[21] Munch, J.R. (2010): "Whose Job Goes Abroad? International Outsourcing and Individual Job Separations," Scandinavian Journal of Economics 112(2), 339-360.

[22] Pavcnik, N. (2002): "Trade liberalization, exit, and productivity improvement: Evidence from Chilean plants," Review of Economic Studies 69 (1), 245-76.

[23] Rauch J. E. (1999): "Network versus Markets in International Trade," Journal of International Economics, 48, 7-35. 
[24] Topalova, P., and A. Khandelwal (2011): "Trade Liberalization and Firm Productivity: The Case of India," Review of Economics and Statistics, 93(3), 995-1009. 


\section{Tables and Figures}

Table 1: Summary Statistics

\begin{tabular}{lcccc}
\hline \hline & mean & sd & $\min$ & $\max$ \\
\hline $\ln (1+$ imports $)$ & 4.47 & 4.45 & 0.00 & 17.72 \\
IMP & 0.57 & 0.49 & 0.00 & 1.00 \\
$\ln (1+$ exports) & 5.69 & 4.54 & 0.00 & 18.37 \\
EXP & 0.66 & 0.47 & 0.00 & 1.00 \\
$\ln ($ regular employment) & 4.92 & 0.84 & 1.10 & 11.53 \\
$\ln$ (wage bill) & 8.63 & 1.03 & 0.00 & 16.27 \\
$\ln$ (share of foreign capital) & 0.06 & 0.18 & 0.00 & 0.69 \\
$\ln$ (total sales) & 10.63 & 1.29 & 0.00 & 18.88 \\
$\ln$ TFP & 3.08 & 2.03 & 0.00 & 98.45 \\
Total Sales to Wage Ratio & 9.49 & 48.96 & 0.00 & 12141.36 \\
OTC (output trade cost) & 10.73 & 8.38 & 1.01 & 50.85 \\
ITC (input trade cost) & 9.83 & 4.86 & 1.71 & 23.30 \\
ITC (input trade cost 2$)$ & 10.86 & 3.74 & 4.32 & 21.26 \\
$\rho-\sigma$ & -0.64 & 3.75 & -23.66 & 1.11 \\
$\rho$ & 3.26 & 1.25 & 1.94 & 10.50 \\
$\sigma$ & 3.90 & 4.52 & 1.49 & 29.01 \\
\hline Observations & 63529 & & & \\
\hline \hline
\end{tabular}

Note: IMP and EXP are importing and exporting dummies.

Manufacturing sample. KSIC from 11 to 33 
Table 2: Impact of Trade Costs on Exports

\begin{tabular}{|c|c|c|c|c|c|c|}
\hline & \multicolumn{3}{|c|}{ Intensive Margin: $\ln (1+$ exports $)$} & \multicolumn{3}{|c|}{ Extensive Margin: Prob(exports $>0$ ) } \\
\hline & (1) & $(2)$ & $(3)$ & (4) & (5) & (6) \\
\hline & \multicolumn{6}{|c|}{ (Panel A: OLS Model with Industry and Year Fixed Effects) } \\
\hline ITC (input trade cost) & $\begin{array}{c}-0.168^{* * *} \\
(0.025)\end{array}$ & & & $\begin{array}{c}-0.017^{* * *} \\
(0.003)\end{array}$ & & \\
\hline ITC2 (input trade cost 2) & & & $\begin{array}{c}-0.109^{* * *} \\
(0.028)\end{array}$ & & & $\begin{array}{c}-0.009^{* * *} \\
(0.003)\end{array}$ \\
\hline OTC (output trade cost) & & $\begin{array}{c}-0.139^{* * *} \\
(0.025)\end{array}$ & $\begin{array}{c}-0.073^{* *} \\
(0.029)\end{array}$ & & $\begin{array}{c}-0.014^{* * *} \\
(0.003)\end{array}$ & $\begin{array}{c}-0.008^{* * *} \\
(0.003)\end{array}$ \\
\hline \multirow[t]{2}{*}{ Observations } & 63529 & 63529 & 63529 & 63529 & 63529 & 63529 \\
\hline & \multicolumn{6}{|c|}{ (Panel B: OLS Model with Firm and Year Fixed Effects) } \\
\hline ITC (input trade cost) & $\begin{array}{c}-0.054^{* * *} \\
(0.010)\end{array}$ & & & $\begin{array}{c}-0.005^{* * *} \\
(0.001)\end{array}$ & & \\
\hline ITC2 (input trade cost 2) & & & $\begin{array}{c}-0.088^{* * *} \\
(0.013)\end{array}$ & & & $\begin{array}{c}-0.007^{* * *} \\
(0.002)\end{array}$ \\
\hline OTC (output trade cost) & & $\begin{array}{c}-0.027^{* * *} \\
(0.008)\end{array}$ & $\begin{array}{l}-0.002 \\
(0.009)\end{array}$ & & $\begin{array}{c}-0.003^{* * *} \\
(0.001)\end{array}$ & $\begin{array}{l}-0.001 \\
(0.001)\end{array}$ \\
\hline Observations & 62390 & 62390 & 62390 & 62390 & 62390 & 62390 \\
\hline
\end{tabular}

Note: Table reports results of OLS regressions using OLS and two-way fixed-effect estimations with firm and year fixed effects. Dependent variables are log of exports and the probability being an exporter. ITC (ITC2) is the input trade cost which is a weighted average of output trade cost (OTC) with weights from input-output table including (excluding) the diagonal elements. Robust standard errors in parentheses are clustered at the industry-by-year level. $\quad{ }^{*} p<.10,{ }^{* *} p<.05,{ }^{* * *} p<.01$ 
Table 3: Impact of Trade Costs on Imports

Intensive Margin: $\ln (1+$ imports $) \quad$ Extensive Margin: Prob(imports $>0$ )

$(1)$

(2)

(3)

(4)

(5)

(6)

(Panel A: OLS Model with Industry and Year Fixed Effects)

ITC (input trade cost) $\quad-0.102^{* * *}$

$-0.016^{* * *}$

$(0.003)$

ITC2 (input trade cost 2)

$-0.152^{* * *}$

$(0.033)$

$-0.020^{* * *}$

$(0.004)$

\begin{tabular}{|c|c|c|c|c|c|c|}
\hline OTC (output trade cost) & & $\begin{array}{c}-0.040^{* *} \\
(0.018)\end{array}$ & $\begin{array}{l}-0.007 \\
(0.020)\end{array}$ & & $\begin{array}{c}-0.007^{* * *} \\
(0.002)\end{array}$ & $\begin{array}{l}-0.003 \\
(0.002)\end{array}$ \\
\hline Observations & 63529 & 63529 & 63529 & 63529 & 63529 & 63529 \\
\hline
\end{tabular}

(Panel B: OLS Model with Firm and Year Fixed Effects)

ITC (input trade cost) $\quad-0.055^{* * *}$

$(0.011)$ $-0.006^{* * *}$

$(0.001)$

ITC2 (input trade cost 2) $-0.050^{* * *}$ $-0.005^{* *}$

OTC (output trade cost)
$(0.015)$

(0.01)

\begin{tabular}{|c|c|c|c|c|c|c|}
\hline OTC (output trade cost) & & $\begin{array}{c}-0.035^{* * *} \\
(0.009)\end{array}$ & $\begin{array}{c}-0.022^{* *} \\
(0.010)\end{array}$ & & $\begin{array}{c}-0.005^{* * *} \\
(0.001)\end{array}$ & $\begin{array}{c}-0.003^{* * *} \\
(0.001)\end{array}$ \\
\hline Observations & 62390 & 62390 & 62390 & 62390 & 62390 & 62390 \\
\hline
\end{tabular}

Note: Table reports results of OLS regressions using OLS and two-way fixed-effect estimations with firm and year fixed effects. Dependent variables are log of imports and the probability being an importer. ITC (ITC2) is the input trade cost which is a weighted average of output trade cost (OTC) with weights from input-output table including (excluding) the diagonal elements. Robust standard errors in parentheses are clustered at the industry-by-year level. $\quad{ }^{*} p<.10,{ }^{* *} p<.05,{ }^{* * *} p<.01$ 
Table 4: Impact of Trade Costs on Firm-Level Employment, Split Sample based on the value of $\rho-\sigma$ or $\sigma$

\begin{tabular}{|c|c|c|c|c|c|c|}
\hline & \multicolumn{5}{|c|}{$($ Panel $A: \rho-\sigma)$} & \\
\hline & $\begin{array}{l}(1) \\
\text { Sub Input }\end{array}$ & $\begin{array}{l}(2) \\
\text { Comp Input }\end{array}$ & $\begin{array}{l}(3) \\
\text { Sub Input }\end{array}$ & $\begin{array}{l}(4) \\
\text { Comp Input }\end{array}$ & $\begin{array}{l}(5) \\
\text { Sub Input }\end{array}$ & $\begin{array}{c}(6) \\
\text { Comp Input }\end{array}$ \\
\hline ITC (input trade cost) & $\begin{array}{c}0.013^{* * *} \\
(0.002)\end{array}$ & $\begin{array}{l}-0.001 \\
(0.002)\end{array}$ & & & & \\
\hline ITC2 (input trade cost 2) & & & & & $\begin{array}{c}0.018^{* * *} \\
(0.002)\end{array}$ & $\begin{array}{c}-0.008^{* * *} \\
(0.002)\end{array}$ \\
\hline OTC (output trade cost) & & & $\begin{array}{c}0.006^{* * *} \\
(0.002)\end{array}$ & $\begin{array}{l}-0.000 \\
(0.001)\end{array}$ & $\begin{array}{l}-0.001 \\
(0.002)\end{array}$ & $\begin{array}{c}0.001 \\
(0.002)\end{array}$ \\
\hline \multirow[t]{3}{*}{ Observations } & 35328 & 26684 & 35328 & 26684 & 35328 & 26684 \\
\hline & \multicolumn{6}{|c|}{$\begin{array}{c}(\text { Panel } B: \sigma) \\
\sigma<\text { mean : Sub Input; } \sigma>=\text { mean: Comp Input }\end{array}$} \\
\hline & Sub Input & $\begin{array}{c}(2) \\
\text { Comp Input }\end{array}$ & $\begin{array}{c}\text { (3) } \\
\text { Sub Input }\end{array}$ & $\begin{array}{c}(4) \\
\text { Comp Input }\end{array}$ & $\begin{array}{c}(5) \\
\text { Sub Input }\end{array}$ & $\begin{array}{c}(6) \\
\text { Comp Input }\end{array}$ \\
\hline ITC (input trade cost) & $\begin{array}{c}0.007^{* * *} \\
(0.001)\end{array}$ & $\begin{array}{l}-0.009 \\
(0.006)\end{array}$ & & & & \\
\hline ITC2 (input trade cost 2) & & & & & $\begin{array}{l}0.007^{* * *} \\
(0.001)\end{array}$ & $\begin{array}{l}-0.005 \\
(0.010)\end{array}$ \\
\hline OTC (output trade cost) & & & $\begin{array}{l}0.003^{* *} \\
(0.001)\end{array}$ & $\begin{array}{l}-0.012^{*} \\
(0.007)\end{array}$ & $\begin{array}{c}0.000 \\
(0.001)\end{array}$ & $\begin{array}{l}-0.011 \\
(0.007)\end{array}$ \\
\hline \multirow[t]{3}{*}{ Observations } & 50361 & 11831 & 50361 & 11831 & 50361 & 11831 \\
\hline & \multicolumn{6}{|c|}{$\begin{array}{c}(\text { Panel } C: \sigma) \\
\sigma<\text { median : Sub Input; } \sigma>=\text { median: Comp Input }\end{array}$} \\
\hline & $\begin{array}{c}\text { (1) } \\
\text { Sub Input }\end{array}$ & $\begin{array}{c}(2) \\
\text { Comp Input }\end{array}$ & $\begin{array}{c}(3) \\
\text { Sub Input }\end{array}$ & $\begin{array}{c}(4) \\
\text { Comp Input }\end{array}$ & $\begin{array}{c}(5) \\
\text { Sub Input }\end{array}$ & $\begin{array}{c}(6) \\
\text { Comp Input }\end{array}$ \\
\hline ITC (input trade cost) & $\begin{array}{c}0.012^{* * *} \\
(0.002)\end{array}$ & $\begin{array}{c}0.002 \\
(0.001)\end{array}$ & & & & \\
\hline ITC2 (input trade cost 2) & & & & & $\begin{array}{c}0.017^{* * *} \\
(0.002)\end{array}$ & $\begin{array}{c}-0.004^{* *} \\
(0.002)\end{array}$ \\
\hline OTC (output trade cost) & & & $\begin{array}{c}0.002 \\
(0.002)\end{array}$ & $\begin{array}{c}0.002 \\
(0.001)\end{array}$ & $\begin{array}{l}-0.001 \\
(0.002)\end{array}$ & $\begin{array}{l}0.003^{* *} \\
(0.001)\end{array}$ \\
\hline Observations & 29219 & 32620 & 29219 & 32620 & 29219 & 32620 \\
\hline Firm Fixed Effects & Yes & Yes & Yes & Yes & Yes & Yes \\
\hline Year Fixed Effects & Yes & Yes & Yes & Yes & Yes & Yes \\
\hline
\end{tabular}

Note: Table reports results of OLS regressions with firm and year fixed effects. Dependent variables are log of employment. ITC (ITC2) is the input trade cost which is a weighted average of output trade cost (OTC) with weights from input-output table including (excluding) the diagonal elements. Robust standard errors in parentheses are clustered at the industry-by-year level. $\rho$ is the input elasticity of substitution, $\sigma$ is the Korean output elasticity of substitution from Broda and Weinstein (2006). $\quad{ }^{*} p<.10,{ }^{* *} p<.05,{ }^{* * *} p<.01$ 
Table 5: The Impact of Trade Costs on Firm-Level Employment, Full Specification

\begin{tabular}{|c|c|c|c|c|c|c|c|c|}
\hline & (1) & $(2)$ & (3) & (4) & (5) & (6) & (7) & (8) \\
\hline $\operatorname{ITC}(\lambda)$ & $\begin{array}{l}0.012^{* *} \\
(0.006)\end{array}$ & $\begin{array}{c}0.006 \\
(0.006)\end{array}$ & & $\begin{array}{c}0.010 \\
(0.007)\end{array}$ & $\begin{array}{c}0.006^{* * *} \\
(0.001)\end{array}$ & $\begin{array}{c}0.006^{* * *} \\
(0.001)\end{array}$ & & $\begin{array}{c}0.005^{* * *} \\
(0.002)\end{array}$ \\
\hline $\mathrm{EXP} \times \lambda$ & & $\begin{array}{l}-0.001 \\
(0.002)\end{array}$ & & $\begin{array}{c}-0.010^{* * *} \\
(0.003)\end{array}$ & & $\begin{array}{l}-0.001^{*} \\
(0.001)\end{array}$ & & $\begin{array}{c}-0.002^{*} \\
(0.001)\end{array}$ \\
\hline $\mathrm{EXP} \times \operatorname{IMP} \times \lambda$ & & $\begin{array}{c}0.013^{* * *} \\
(0.001)\end{array}$ & & $\begin{array}{c}0.016^{* * *} \\
(0.002)\end{array}$ & & $\begin{array}{l}0.001^{*} \\
(0.001)\end{array}$ & & $\begin{array}{l}-0.000 \\
(0.001)\end{array}$ \\
\hline $\mathrm{IMP} \times(\rho-\sigma) \times \lambda$ & $\begin{array}{c}0.008^{* * *} \\
(0.001)\end{array}$ & $\begin{array}{c}0.008^{* * *} \\
(0.001)\end{array}$ & & $\begin{array}{c}0.009^{* * *} \\
(0.001)\end{array}$ & $\begin{array}{c}0.002^{* * *} \\
(0.000)\end{array}$ & $\begin{array}{c}0.002^{* * *} \\
(0.000)\end{array}$ & & $\begin{array}{c}0.002^{* * *} \\
(0.000)\end{array}$ \\
\hline $\operatorname{OTC}(\tau)$ & & & $\begin{array}{c}0.003 \\
(0.006)\end{array}$ & $\begin{array}{l}-0.002 \\
(0.007)\end{array}$ & & & $\begin{array}{c}0.005^{* * *} \\
(0.001)\end{array}$ & $\begin{array}{c}0.003^{* * *} \\
(0.001)\end{array}$ \\
\hline $\mathrm{EXP} \times \tau$ & & & $\begin{array}{c}0.000 \\
(0.001)\end{array}$ & $\begin{array}{c}0.006^{* * *} \\
(0.002)\end{array}$ & & & $\begin{array}{l}-0.001 \\
(0.000)\end{array}$ & $\begin{array}{c}0.000 \\
(0.001)\end{array}$ \\
\hline $\mathrm{EXP} \times \operatorname{IMP} \times \tau$ & & & $\begin{array}{c}0.009^{* * *} \\
(0.001)\end{array}$ & $\begin{array}{l}-0.000 \\
(0.002)\end{array}$ & & & $\begin{array}{l}0.001^{*} \\
(0.000)\end{array}$ & $\begin{array}{c}0.001 \\
(0.001)\end{array}$ \\
\hline $\mathrm{EXP}=1$ & $\begin{array}{c}0.291^{* * *} \\
(0.008)\end{array}$ & $\begin{array}{c}0.253^{* * *} \\
(0.017)\end{array}$ & $\begin{array}{c}0.253^{* * *} \\
(0.013)\end{array}$ & $\begin{array}{c}0.273^{* * *} \\
(0.025)\end{array}$ & $\begin{array}{c}0.026^{* * *} \\
(0.004)\end{array}$ & $\begin{array}{c}0.036^{* * *} \\
(0.008)\end{array}$ & $\begin{array}{c}0.030^{* * *} \\
(0.006)\end{array}$ & $\begin{array}{c}0.049^{* * *} \\
(0.011)\end{array}$ \\
\hline $\mathrm{IMP}=1$ & $\begin{array}{c}0.268^{* * *} \\
(0.008)\end{array}$ & $\begin{array}{c}0.177^{* * *} \\
(0.012)\end{array}$ & $\begin{array}{c}0.199^{* * *} \\
(0.011)\end{array}$ & $\begin{array}{c}0.142^{* * *} \\
(0.013)\end{array}$ & $\begin{array}{c}0.024^{* * *} \\
(0.003)\end{array}$ & $\begin{array}{c}0.018^{* * *} \\
(0.005)\end{array}$ & $\begin{array}{c}0.018^{* * *} \\
(0.004)\end{array}$ & $\begin{array}{c}0.020^{* * *} \\
(0.005)\end{array}$ \\
\hline Industry FE & Yes & Yes & Yes & Yes & No & No & No & No \\
\hline Firm FE & No & No & No & No & Yes & Yes & Yes & Yes \\
\hline Year FE & Yes & Yes & Yes & Yes & Yes & Yes & Yes & Yes \\
\hline Observations & 63529 & 63529 & 63529 & 63529 & 62390 & 62390 & 62390 & 62390 \\
\hline
\end{tabular}

Note: All tables include year fixed effects. $\lambda$ is the modified input trade cost, $\tau$ is the output trade cost. $\rho$ is the input elasticity of substitution, $\sigma$ is the Korean output elasticity of substitution from Broda and Weinstein (2006). In columns (4) and (8), where output trade cost $(\tau)$ is also included, we have replaced ITC with ITC2 as our measure of input trade cost $(\lambda)$ to to avoid the high correlation between input and output trade cost. Robust standard errors in the parentheses are clustered at the industry-by-year level. $\quad{ }^{*} p<.10,{ }^{* *} p<.05,{ }^{* * *} p<.01$ 


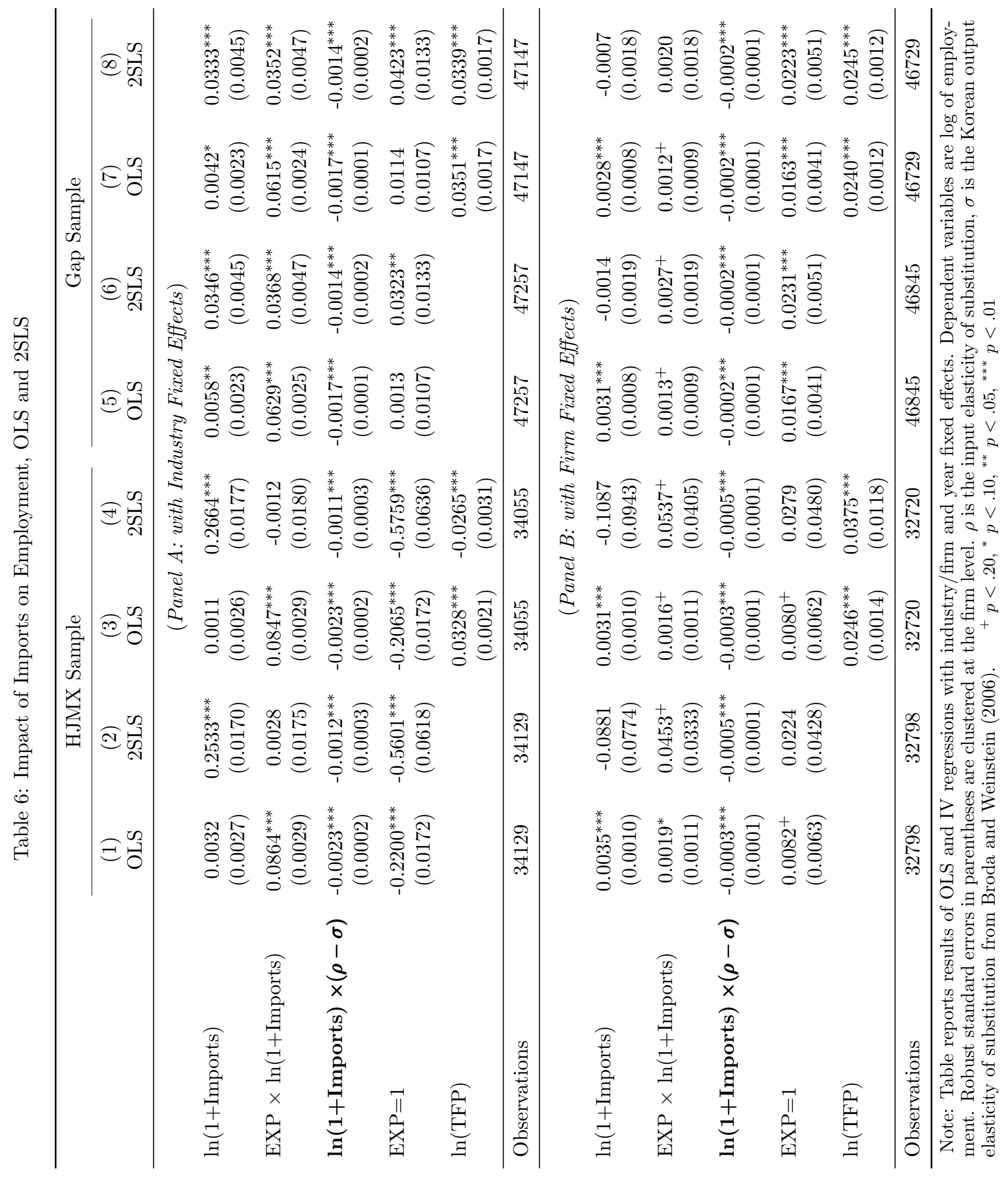


Table 7: First Stage Result

\begin{tabular}{|c|c|c|c|c|}
\hline & \multicolumn{2}{|c|}{ HJMX Sample } & \multicolumn{2}{|c|}{ Gap Sample } \\
\hline & $(1)$ & $(2)$ & $(3)$ & $(4)$ \\
\hline \multicolumn{5}{|c|}{ First Endogenous Variable: $\ln (1+$ imports $)$} \\
\hline $\ln (\operatorname{Imports} I V)$ & $\begin{array}{c}0.4250^{* * *} \\
(0.0198)\end{array}$ & $\begin{array}{c}-0.0382 \\
(0.0707)\end{array}$ & $\begin{array}{c}0.2083^{* * *} \\
(0.0036)\end{array}$ & $\begin{array}{c}0.1651^{\text {*** }} \\
(0.0037)\end{array}$ \\
\hline EXP $\times \ln ($ Imports IV $)$ & $\begin{array}{c}0.2447^{* * *} \\
(0.0210)\end{array}$ & $\begin{array}{c}0.2123^{* * *} \\
(0.0243)\end{array}$ & $\begin{array}{c}0.2415^{* * *} \\
(0.0043)\end{array}$ & $\begin{array}{c}0.1843^{* * *} \\
(0.0044)\end{array}$ \\
\hline $\ln (\operatorname{Imports} \mathrm{IV}) \times(\rho-\sigma)$ & $\begin{array}{c}-0.0026^{* * *} \\
(0.0008)\end{array}$ & $\begin{array}{c}-0.0008 \\
(0.0006)\end{array}$ & $\begin{array}{c}-0.0028^{* * *} \\
(0.0004)\end{array}$ & $\begin{array}{c}-0.0018^{* * *} \\
(0.0004)\end{array}$ \\
\hline $\mathrm{EXP}=1$ & $\begin{array}{c}-0.5099^{+} \\
(0.3258)\end{array}$ & $\begin{array}{c}-0.5107^{+} \\
(0.3785)\end{array}$ & $\begin{array}{c}-0.2518^{* * *} \\
(0.0514)\end{array}$ & $\begin{array}{l}0.0899^{+} \\
(0.0561)\end{array}$ \\
\hline $\ln (\mathrm{TFP})$ & $\begin{array}{c}0.1439^{* * *} \\
(0.0089)\end{array}$ & $\begin{array}{c}0.1994^{* * *} \\
(0.0176)\end{array}$ & $\begin{array}{c}0.1486^{* * *} \\
(0.0064)\end{array}$ & $\begin{array}{c}0.1622^{* * *} \\
(0.0130)\end{array}$ \\
\hline \multicolumn{5}{|c|}{ Second Endogenous Variable: $\ln (1+$ imports $) \times(\rho-\sigma)$} \\
\hline $\ln ($ Imports IV $)$ & $\begin{array}{c}-0.2381^{* *} \\
(0.0959)\end{array}$ & $\begin{array}{c}-3.4109^{* * *} \\
(0.3494)\end{array}$ & $\begin{array}{c}0.1485^{* * *} \\
(0.0177)\end{array}$ & $\begin{array}{c}0.1300^{* * *} \\
(0.0183)\end{array}$ \\
\hline $\mathrm{EXP} \times \ln ($ Imports IV $)$ & $\begin{array}{c}0.1999^{* *} \\
(0.1017)\end{array}$ & $\begin{array}{c}0.3121^{* * *} \\
(0.1203)\end{array}$ & $\begin{array}{c}-0.1524^{* * *} \\
(0.0214)\end{array}$ & $\begin{array}{c}-0.1109^{* * *} \\
(0.0219)\end{array}$ \\
\hline $\ln (\operatorname{Imports} \mathrm{IV}) \times(\rho-\sigma)$ & $\begin{array}{c}0.7244^{* * *} \\
(0.0037)\end{array}$ & $\begin{array}{c}0.5267^{* * *} \\
(0.0031)\end{array}$ & $\begin{array}{c}0.5649^{* * *} \\
(0.0019)\end{array}$ & $\begin{array}{c}0.4748^{* * *} \\
(0.0020)\end{array}$ \\
\hline $\mathrm{EXP}=1$ & $\begin{array}{c}-4.7909^{* * *} \\
(1.5742)\end{array}$ & $\begin{array}{c}-6.1715^{* * *} \\
(1.8709)\end{array}$ & $\begin{array}{l}0.3259^{+} \\
(0.2543)\end{array}$ & $\begin{array}{c}0.1584 \\
(0.2804)\end{array}$ \\
\hline $\ln (\mathrm{TFP})$ & $\begin{array}{l}-0.0489 \\
(0.0429)\end{array}$ & $\begin{array}{c}-0.2369^{* * *} \\
(0.0871)\end{array}$ & $\begin{array}{c}-0.0885^{* * *} \\
(0.0316)\end{array}$ & $\begin{array}{c}-0.1962^{* * *} \\
(0.0653)\end{array}$ \\
\hline \multicolumn{5}{|c|}{ Third Endogenous Variable: $E X P \times \ln (1+$ imports $)$} \\
\hline $\ln ($ Imports IV $)$ & $\begin{array}{c}0.0687^{* * *} \\
(0.0177)\end{array}$ & $\begin{array}{c}-0.2821^{* * *} \\
(0.0631)\end{array}$ & $\begin{array}{l}-0.0022 \\
(0.0032)\end{array}$ & $\begin{array}{c}-0.0149^{* * *} \\
(0.0033)\end{array}$ \\
\hline $\mathrm{EXP} \times \ln ($ Imports IV $)$ & $\begin{array}{c}0.6017^{* * *} \\
(0.0188)\end{array}$ & $\begin{array}{c}0.5037^{* * *} \\
(0.0217)\end{array}$ & $\begin{array}{c}0.4562^{* * *} \\
(0.0039)\end{array}$ & $\begin{array}{c}0.3714^{* * *} \\
(0.0039)\end{array}$ \\
\hline $\ln (\operatorname{Imports} \mathrm{IV}) \times(\rho-\sigma)$ & $\begin{array}{c}-0.0027^{* * *} \\
(0.0007)\end{array}$ & $\begin{array}{c}-0.0009^{*} \\
(0.0006)\end{array}$ & $\begin{array}{c}-0.0026^{* * *} \\
(0.0003)\end{array}$ & $\begin{array}{c}-0.0018^{* * *} \\
(0.0004)\end{array}$ \\
\hline $\mathrm{EXP}=1$ & $\begin{array}{c}-2.7919^{* * *} \\
(0.2909)\end{array}$ & $\begin{array}{c}-2.2199^{* * *} \\
(0.3379)\end{array}$ & $\begin{array}{c}-0.3189^{* * *} \\
(0.0459)\end{array}$ & $\begin{array}{l}0.0737^{+} \\
(0.0502)\end{array}$ \\
\hline $\ln (\mathrm{TFP})$ & $\begin{array}{c}0.1269^{* * *} \\
(0.0079)\end{array}$ & $\begin{array}{c}0.1792^{* * *} \\
(0.0157)\end{array}$ & $\begin{array}{c}0.1313^{* * *} \\
(0.0057)\end{array}$ & $\begin{array}{c}0.1394^{* * *} \\
(0.0117)\end{array}$ \\
\hline Cragg-Donald Wald F-Stat & 482.66 & 0.925 & 5295.86 & 3370.20 \\
\hline Anderson-Rubin Wald F-Stat & 2791.41 & 9.33 & 709.95 & 5.19 \\
\hline Angrist-Pischke F-Stat & 1031.38 & 41.49 & 928.70 & 105.73 \\
\hline Stock-Yogo Critical Value (5\%) & 13.91 & 13.91 & 13.91 & 13.91 \\
\hline Stock-Yogo Critical Value (10\%) & 9.08 & 9.08 & 9.08 & 9.08 \\
\hline Industry Fixed Effects & Yes & $\cdot$ & Yes & $\cdot$ \\
\hline Firm Fixed Effects & . & Yes & . & Yes \\
\hline Year Fixed Effects & Yes & Yes & Yes & Yes \\
\hline Observations & 34055 & 32720 & 47147 & 46729 \\
\hline
\end{tabular}


Table 8: Test of Balacing Hypothesis: Before vs. After Matching

\begin{tabular}{|c|c|c|c|c|c|c|}
\hline \multirow[b]{2}{*}{ Variable } & \multirow[b]{2}{*}{$\begin{array}{c}\text { Sample } \\
\text { (Unmatched/Matched) }\end{array}$} & \multicolumn{3}{|c|}{ Mean } & \multicolumn{2}{|c|}{ t-test } \\
\hline & & Treated & Control & \%bias & $\mathrm{t}$ & p-value \\
\hline \multirow[t]{2}{*}{$\operatorname{lnTFP}$} & $\mathrm{U}$ & 3.7124 & 3.5875 & 5.1 & 1.91 & 0.056 \\
\hline & M & 3.5765 & 3.4641 & 4.6 & 1.97 & 0.049 \\
\hline \multirow[t]{2}{*}{$\operatorname{lnSale}$} & $\mathrm{U}$ & 10.895 & 9.9338 & 95.7 & 34.22 & 0.000 \\
\hline & M & 10.622 & 10.577 & 4.4 & 1.88 & 0.060 \\
\hline \multirow[t]{2}{*}{ lnShare } & $\mathrm{U}$ & .05475 & .00354 & 42.0 & 14.02 & 0.000 \\
\hline & M & .00386 & .00364 & 0.2 & 0.29 & 0.775 \\
\hline \multirow[t]{2}{*}{ lnMaterial } & $\mathrm{U}$ & 10.118 & 8.3559 & 80.8 & 31.83 & 0.000 \\
\hline & M & 9.8386 & 9.792 & 2.1 & 1.47 & 0.142 \\
\hline \multirow[t]{2}{*}{$\ln$ Asset } & $\mathrm{U}$ & 10.817 & 9.6084 & 118.0 & 42.22 & 0.000 \\
\hline & M & 10.539 & 10.502 & 3.7 & 1.56 & 0.119 \\
\hline \multirow[t]{2}{*}{ lnWage } & $\mathrm{U}$ & 8.836 & 8.1705 & 87.6 & 30.89 & 0.000 \\
\hline & M & 8.6011 & 8.6004 & 0.1 & 0.04 & 0.971 \\
\hline \multirow[t]{2}{*}{ lnShareXlnAsset } & $\mathrm{U}$ & .6173 & .03396 & 42.8 & 14.22 & 0.000 \\
\hline & M & .03998 & .0387 & 0.1 & 0.16 & 0.872 \\
\hline \multirow[t]{2}{*}{ lnTFPXlnShare } & $\mathrm{U}$ & .22995 & .00356 & 39.1 & 12.87 & 0.000 \\
\hline & M & .00819 & .009 & -0.1 & -0.48 & 0.633 \\
\hline \multirow[t]{2}{*}{ lnSaleXlnMaterial } & $\mathrm{U}$ & 111.73 & 84.406 & 92.7 & 34.68 & 0.000 \\
\hline & M & 105.49 & 104.38 & 3.8 & 2.01 & 0.045 \\
\hline \multirow[t]{2}{*}{$\operatorname{lnTFPXlnAsset}$} & $\mathrm{U}$ & 40.625 & 34.925 & 21.2 & 7.87 & 0.000 \\
\hline & M & 37.936 & 36.478 & 5.4 & 2.33 & 0.020 \\
\hline \multirow[t]{2}{*}{ lnTFPXlnMaterial } & $\mathrm{U}$ & 39.418 & 34.117 & 17.7 & 6.60 & 0.000 \\
\hline & M & 36.843 & 35.366 & 4.9 & 2.15 & 0.032 \\
\hline \multirow[t]{2}{*}{ lnMaterialXlnMaterial } & $\mathrm{U}$ & 104.56 & 77.121 & 89.7 & 33.47 & 0.000 \\
\hline & M & 98.372 & 97.139 & 4.0 & 2.07 & 0.038 \\
\hline \multirow[t]{2}{*}{$\operatorname{lnTFPXInSale}$} & $\mathrm{U}$ & 41.807 & 37.12 & 15.7 & 5.84 & 0.000 \\
\hline & M & 39.111 & 37.608 & 5.0 & 2.17 & 0.030 \\
\hline \multirow[t]{2}{*}{ lnTFPXlnWage } & $\mathrm{U}$ & 33.073 & 29.225 & 17.9 & 6.64 & 0.000 \\
\hline & M & 30.852 & 29.871 & 4.6 & 1.95 & 0.051 \\
\hline \multirow[t]{2}{*}{ lnMaterialXlnWage } & $\mathrm{U}$ & 90.31 & 68.325 & 98.2 & 36.64 & 0.000 \\
\hline & M & 85.083 & 84.599 & 2.2 & 1.21 & 0.226 \\
\hline \multirow[t]{2}{*}{$\operatorname{lnSaleX\operatorname {ln}Asset}$} & $\mathrm{U}$ & 119.07 & 96 & 108.3 & 38.19 & 0.000 \\
\hline & M & 112.66 & 111.7 & 4.5 & 1.99 & 0.047 \\
\hline \multirow{2}{*}{ lnAssetXlnWage } & $\mathrm{U}$ & 96.5 & 78.752 & 107.7 & 37.59 & 0.000 \\
\hline & M & 91.143 & 90.773 & 2.2 & 0.98 & 0.328 \\
\hline \multirow[t]{2}{*}{ lnWageXlnWage } & $\mathrm{U}$ & 78.912 & 67.074 & 85.4 & 29.87 & 0.000 \\
\hline & M & 74.438 & 74.41 & 0.2 & 0.09 & 0.929 \\
\hline \multirow[t]{2}{*}{$\ln$ AssetXlnAsset } & $\mathrm{U}$ & 118.38 & 93.048 & 114.6 & 40.53 & 0.000 \\
\hline & M & 111.95 & 111.05 & 4.1 & 1.76 & 0.079 \\
\hline lnSaleXlnSale & $\mathrm{U}$ & 120.03 & 99.373 & 93.9 & 33.24 & 0.000 \\
\hline & M & 113.65 & 112.61 & 4.7 & 2.06 & 0.040 \\
\hline lnShareXlnMaterial & $\mathrm{U}$ & .58913 & .00622 & 45.6 & 15.01 & 0.000 \\
\hline & M & .03449 & .03534 & -0.1 & -0.13 & 0.900 \\
\hline lnSaleXlnWage & $\mathrm{U}$ & 97.168 & 81.413 & 96.0 & 33.54 & 0.000 \\
\hline & $\mathrm{M}$ & 91.831 & 91.41 & 2.6 & 1.12 & 0.262 \\
\hline
\end{tabular}


Table 9: Propensity Score Matching Estimation: Firm-Level Imports and Employment

\begin{tabular}{|c|c|c|c|c|c|c|}
\hline & \multicolumn{3}{|c|}{ PSM Results } & \multicolumn{3}{|c|}{ PSM-DID Results } \\
\hline & (1) & $(2)$ & $(3)$ & $(4)$ & $(5)$ & $(6)$ \\
\hline$I M P=1$ & $\begin{array}{c}0.2235^{* * *} \\
(0.0088)\end{array}$ & $\begin{array}{c}0.2209^{* * *} \\
(0.0089)\end{array}$ & $\begin{array}{c}0.0976^{* * *} \\
(0.0204)\end{array}$ & $\begin{array}{c}0.0257^{* * *} \\
(0.0051)\end{array}$ & $\begin{array}{c}0.0248^{* * *} \\
(0.0052)\end{array}$ & $\begin{array}{c}0.0161^{+} \\
(0.0108)\end{array}$ \\
\hline$I M P \times E X P$ & & & $\begin{array}{c}0.0629^{* * *} \\
(0.0232)\end{array}$ & & & $\begin{array}{c}0.0034 \\
(0.0119)\end{array}$ \\
\hline$I M P \times(\rho-\sigma)$ & & $\begin{array}{c}-0.0063^{* * *} \\
(0.0018)\end{array}$ & $\begin{array}{c}-0.0062^{\text {*** }} \\
(0.0017)\end{array}$ & & $\begin{array}{c}-0.0024^{* *} \\
(0.0012)\end{array}$ & $\begin{array}{c}-0.0023^{* *} \\
(0.0012)\end{array}$ \\
\hline$E X P=1$ & & & $\begin{array}{c}0.1427^{* * *} \\
(0.0117)\end{array}$ & & & $\begin{array}{c}0.0215^{* * *} \\
(0.0068)\end{array}$ \\
\hline Firm FE & No & No & No & Yes & Yes & Yes \\
\hline Year FE & Yes & Yes & Yes & Yes & Yes & Yes \\
\hline Observations & 18138 & 18138 & 18138 & 18138 & 18138 & 18138 \\
\hline
\end{tabular}

Note: All estimations include year fixed effects. Robust standard errors in parentheses are clustered at the firm level. $\rho$ is the input elasticity of substitution, $\sigma$ is the Korean output elasticity of substitution from Broda and Weinstein (2006). $\quad{ }^{+} p<.20,{ }^{*} p<.10,{ }^{* *} p<.05,{ }^{* * *} p<.01$ 
Figure 1: Imports - Instrument Correlation Plot

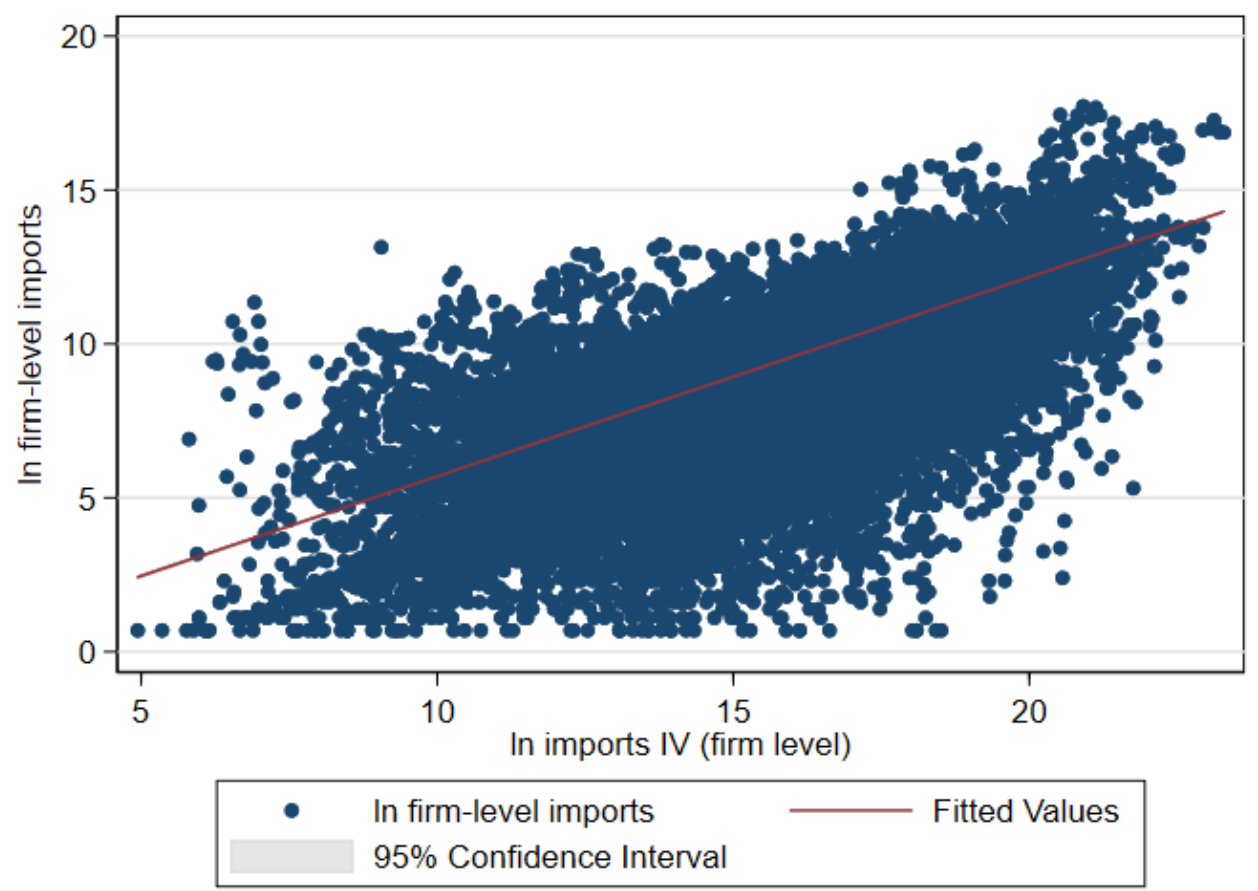

Source: Coefficient $=0.647$, Standard error $=0.003, \mathrm{R}$-squared $=0.476$

Figure 2: Propensity Scores Before vs. After Matching

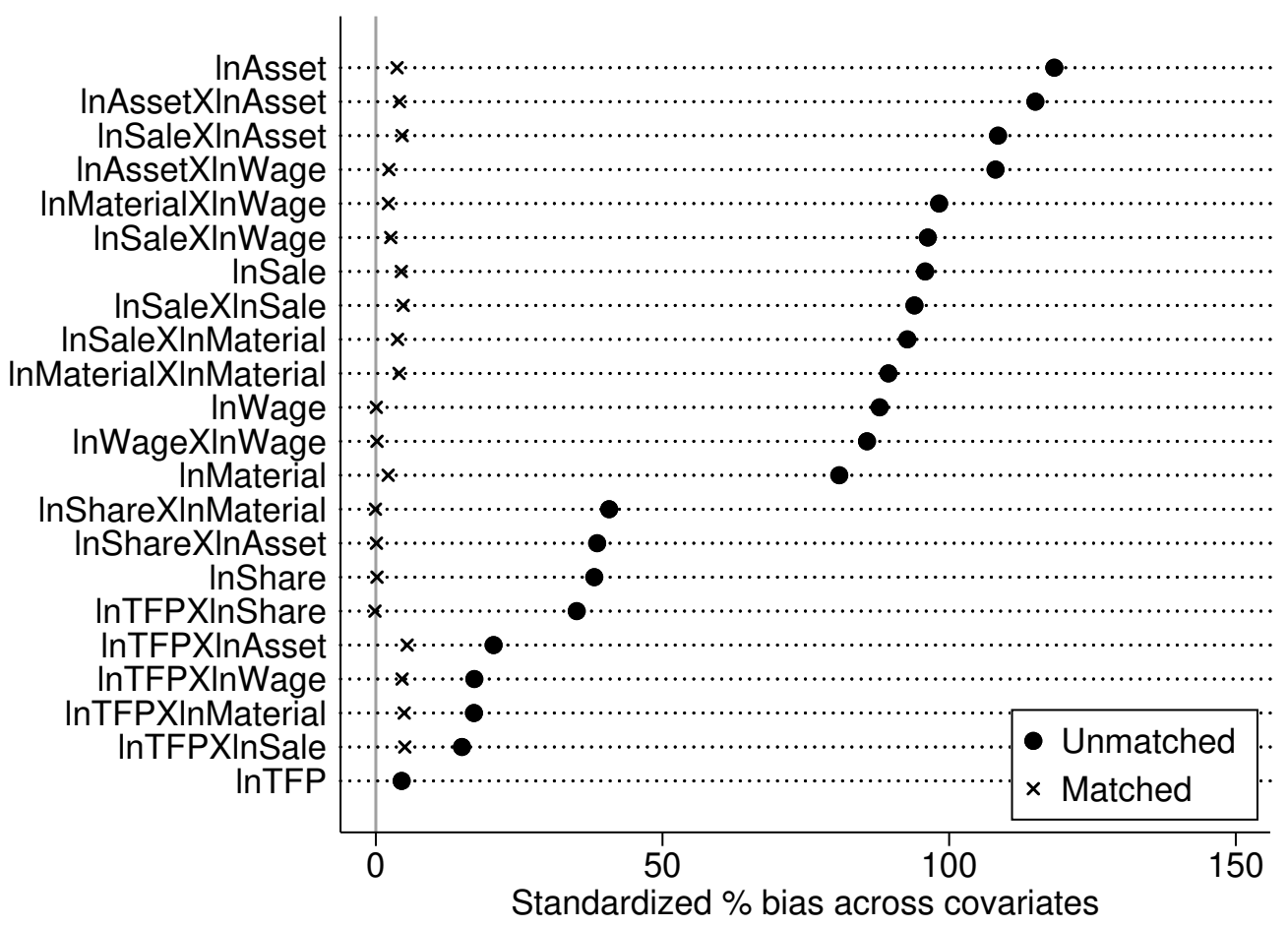




\section{Appendix}

\subsection{Condition for the marginal surviving firm to neither export nor offshore}

For the marginal firm to not export, it must be the case that

$$
\left(\left(\frac{\sigma}{\sigma-1}\right) \frac{c_{n}}{\widehat{\varphi}}\right)^{1-\sigma}\left(\frac{\tau^{1-\sigma} A}{\sigma}\right)<f_{x}
$$

That is, even if the firm gets the lowest possible draw of exporting variable cost $t_{x}$ which is 1 , it still cannot cover the fixed cost of exporting, and hence it doesn't export.

In order for this firm to not offshore it must be the case that

$$
\left(\left(\frac{\sigma}{\sigma-1}\right) \frac{\left.c_{o}(\psi)\right|_{t_{o}=1}}{\widehat{\varphi}}\right)^{1-\sigma} \frac{P^{\sigma-\eta} \mathbb{L}}{\sigma}<f+f_{o}
$$

That is, even if the firm gets the most favorable draw of $t_{o}$ which is 1 , it still doesn't find it worthwhile to offshore. Since (9) is satisfied for this firm, the above can be written as

$$
\left(\frac{c_{n}}{\left.c_{o}(\psi)\right|_{t_{o}=1}}\right)^{\sigma-1} f<f+f_{o}
$$

So, if the above condition is satisfied, then the marginal existing firm doesn't offshore.

Can this firm do both if either of them alone is not possible? This will not be possible if

$$
\left(\left(\frac{\sigma}{\sigma-1}\right) \frac{\left.c_{o}(\psi)\right|_{t_{o}=1}}{\widehat{\varphi}}\right)^{1-\sigma}\left(\frac{P^{\sigma-\eta} \mathbb{L}+\tau^{1-\sigma} A}{\sigma}\right)-f-f_{o}-f_{x}<0
$$

Substituting out $P^{\sigma-\eta}$ using (9) the above can be written as

$$
\left(\frac{c_{n}}{\left.c_{o}(\psi)\right|_{t_{o}=1}}\right)^{\sigma-1} f-f-f_{o}+\left(\left(\frac{\sigma}{\sigma-1}\right) \frac{\left.c_{o}(\psi)\right|_{t_{o}=1}}{\widehat{\varphi}}\right)^{1-\sigma} \frac{\tau^{1-\sigma} A}{\sigma}-f_{x}<0
$$

In light of (25) a sufficient condition for the above is that

$$
\left(\left(\frac{\sigma}{\sigma-1}\right) \frac{\left.c_{o}(\psi)\right|_{t_{o}=1}}{\widehat{\varphi}}\right)^{1-\sigma}\left(\frac{\tau^{1-\sigma} A}{\sigma}\right)-f_{x}<0
$$

We know that the firm cannot export when it is not offshoring: $\left(\left(\frac{\sigma}{\sigma-1}\right) \frac{c_{n}}{\varphi}\right)^{1-\sigma}\left(\frac{\tau^{1-\sigma} A}{\sigma}\right)<f_{x}$. In order for this firm to not export when offshoring a sufficient condition is $\left(\left(\frac{\sigma}{\sigma-1}\right) \frac{\left.c_{o}(\psi)\right|_{t_{o}=1}}{\widehat{\varphi}}\right)^{1-\sigma}\left(\frac{\tau^{1-\sigma} A}{\sigma}\right)<$ 
$f_{x}$. Since if this condition is satisfied, the condition $\left(\left(\frac{\sigma}{\sigma-1}\right) \frac{c_{n}}{\widehat{\varphi}}\right)^{1-\sigma}\left(\frac{\tau^{1-\sigma} A}{\sigma}\right)<f_{x}$ is satisfied as well. Therefore, the condition needed for the marginal firm to neither export nor offshore is

$$
\begin{aligned}
\left(\frac{c_{n}}{\left.c_{o}(\psi)\right|_{t_{o}=1}}\right)^{\sigma-1} f & <f+f_{o} ; \\
\left(\left(\frac{\sigma}{\sigma-1}\right) \frac{\left.c_{o}(\psi)\right|_{t_{o}=1}}{\widehat{\varphi}}\right)^{1-\sigma}\left(\frac{\tau^{1-\sigma} A}{\sigma}\right) & <f_{x} .
\end{aligned}
$$

Suppose $A$ is proportional to the domestic market size: $A=\mu P^{\sigma-\eta} \mathbb{L}$, where $\mu$ is the proportionality factor. Now, the second condition above becomes

$$
\left(\frac{c_{n}}{\left.c_{o}(\psi)\right|_{t_{o}=1}}\right)^{\sigma-1} \mu \tau^{1-\sigma} f<f_{x}
$$

That is, the common exporting costs $\left(\tau\right.$ and $f_{x}$ ) should be sufficiently large so that even if the firm gets the best possible draw of firm specific trading cost, it still doesn’t want to export.

\subsection{Existence proof}

We show that $\frac{d \Pi}{d \widehat{\varphi}}<0$. Taking the derivative of (11) with respect to $\widehat{\varphi}$ obtain

$$
\frac{d \Pi}{d \widehat{\varphi}}=-\int_{t_{o}} \int_{t_{x}} \pi\left(\left.\psi\right|_{\widehat{\varphi}}, \widehat{\varphi} ; \tau, \lambda\right) g(\psi) d t_{x} d t_{o}+\int_{\widehat{\varphi}}^{\infty} \int_{t_{o}} \int_{t_{x}} \frac{\partial \pi(\psi, \widehat{\varphi} ; \tau, \lambda)}{\partial \widehat{\varphi}} g(\psi) d t_{x} d t_{o} d \varphi,
$$

where $\left.\psi\right|_{\widehat{\varphi}}=\left(\widehat{\varphi}, t_{x}, t_{o}\right)$. Next, note that $\pi\left(\left.\psi\right|_{\widehat{\varphi}}, \widehat{\varphi} ; \tau, \lambda\right)=0$ for all $t_{x}, t_{o}$ because a firm with productivity $\widehat{\varphi}$ neither offshores nor exports and the net profits are zero for this firm by construction. Moreover $\frac{\partial \pi(\psi, \widehat{\varphi} ; \tau, \lambda)}{\partial \widehat{\varphi}}<0$ as can be easily verified from (10). Therefore, $\frac{d \Pi}{d \widehat{\varphi}}<0$, and hence the equilibrium exists if the initial conditions are correct. We need $\Pi>f_{e}$ when $\widehat{\varphi} \rightarrow \varphi_{\min }$ and $\Pi<f_{e}$ when $\widehat{\varphi} \rightarrow \infty$.

\subsection{Impact of changes in $\tau$ and $\lambda$ on $\widehat{\varphi}$}

The free entry condition (11) implies

$$
\frac{d \Pi}{d \tau} \equiv \frac{\partial \Pi}{\partial \widehat{\varphi}} \frac{d \widehat{\varphi}}{d \tau}+\frac{\partial \Pi}{\partial \tau}=0
$$


From the expression for $\Pi$ in (11)

$$
\frac{\partial \Pi}{\partial \tau} \equiv \int_{\widehat{\varphi}}^{\infty} \int_{t_{o}} \int_{t_{x}} \frac{\partial \pi(\psi, \widehat{\varphi} ; \tau, \lambda)}{\partial \tau} g(\psi) d t_{x} d t_{o} d \varphi<0
$$

The inequality above follows from the fact that $\frac{\partial \pi(\psi, \widehat{\varphi} ; \tau, \lambda)}{\partial \tau} \leq 0$ (easily verified from (10)) for any $\psi$. Since (26) yields $\frac{\partial \Pi}{\partial \widehat{\varphi}}<0$, we get

$$
\frac{d \widehat{\varphi}}{d \tau}=-\frac{\partial \Pi}{\partial \tau} / \frac{\partial \Pi}{\partial \widehat{\varphi}}<0
$$

Similarly,

$$
\frac{d \Pi}{d \lambda} \equiv \frac{\partial \Pi}{\partial \widehat{\varphi}} \frac{d \widehat{\varphi}}{d \lambda}+\frac{\partial \Pi}{\partial \lambda}=0
$$

Again, from the expression for $\Pi$ in (11)

$$
\frac{\partial \Pi}{\partial \lambda} \equiv \int_{\widehat{\varphi}}^{\infty} \int_{t_{o}} \int_{t_{x}} \frac{\partial \pi(\psi, \widehat{\varphi} ; \tau, \lambda)}{\partial \lambda} g(\psi) d t_{x} d t_{o} d \varphi<0
$$

Once again, the inequality above follows from the fact that $\frac{\partial \pi(\psi, \widehat{\varphi} ; \tau, \lambda)}{\partial \lambda} \leq 0$ for any $\psi$ as is easily verified from (10). Therefore,

$$
\frac{d \widehat{\varphi}}{d \lambda}=-\frac{\partial \Pi}{\partial \lambda} / \frac{\partial \Pi}{\partial \widehat{\varphi}}<0
$$

\subsection{Impact of trade costs on firm level trade}

Since the export demand for a firm is $z^{x}(\psi)=p^{x}(\psi)^{-\sigma} A=\left(\left(\frac{\sigma}{\sigma-1}\right) \frac{\tau t_{x} c_{s}(\psi)}{\varphi}\right)^{-\sigma} A$, clearly, $\frac{\partial z^{x}(\psi)}{\partial \tau}<$ 0 , that is, a decrease in the output trade cost increases exports. It also follows that the revenue from exporting is $z^{x}(\psi) p^{x}(\psi)=p^{x}(\psi)^{1-\sigma} A=\left(\left(\frac{\sigma}{\sigma-1}\right) \frac{\tau t_{x} c_{s}(\psi)}{\varphi}\right)^{1-\sigma} A$. Therefore, $\frac{\partial z^{x}(\psi) p^{x}(\psi}{\partial \tau}<0$. That is, a lower output trade cost increases export revenue, and hence given the fixed cost of exporting, a firm is more likely to export.

It can also be verified that $\frac{\partial z^{x}(\psi)}{\partial \lambda} \leq 0$ because $\frac{\partial c_{s}(\psi)}{\partial \lambda} \geq 0$. Recall from the text that when $s=o$, $\frac{d c_{o}(\psi)}{d \lambda}>0$ and when $s=n$, then $\frac{d c_{n}(\psi)}{d \lambda}=0$. That is, a decrease in the offshoring cost also increases exports and increases the probability of a firm exporting.

Given the unit cost for $Y$ in (5), Shephard's lemma implies the following expression for firm level imports or offshoring derived from the domestic sales of a firm.

$$
M^{d}=\left((1-\alpha)^{\rho} c_{s}(\psi)^{\rho} / \varphi\right) p_{o}^{-\rho} p(\psi)^{-\sigma} P^{\sigma-\eta} \mathbb{L}
$$


Since the price of offshored input is $p_{o}(\psi)=\lambda t_{o} p_{M}^{*}$, the above can be written as

$$
M^{d}=\left((1-\alpha)^{\rho} c_{s}(\psi)^{\rho} / \varphi\right)\left(t_{o} p_{M}^{*}\right)^{1-\rho} \lambda^{-\rho} p(\psi)^{-\sigma} P^{\sigma-\eta} \mathbb{L}
$$

Next, substituting out $p(\psi)$ and $P$ in the above expression using equations (6) and (9) obtain

$$
M^{d}=(1-\alpha)^{\rho}\left(t_{o} p_{M}^{*}\right)^{-\rho} \lambda^{-\rho}(\sigma-1)\left(c_{s}(\psi)^{\rho-\sigma}\right)\left(\frac{\varphi c_{n}}{\widehat{\varphi}}\right)^{\sigma-1} f
$$

Taking the $\log$ of the above obtain

$$
\log M^{d}(\psi)=\text { cons } \tan t-\rho \log \lambda+(\rho-\sigma) \log \left(c_{s}(\psi)\right)+(\sigma-1)(\log \varphi-\log \widehat{\varphi})
$$

Verify that the direct effect of a change in $\lambda$ on imports (ignoring the effect on $\widehat{\varphi}$ ) is as follows.

$$
\frac{\partial \log M^{d}(\psi)}{\partial \lambda}=-\frac{\rho}{\lambda}+\frac{(\rho-\sigma)}{\lambda} \frac{(1-\alpha)^{\rho}\left(\lambda t_{o} p_{M}^{*}\right)^{1-\rho}}{\alpha^{\rho}+(1-\alpha)^{\rho}\left(\lambda t_{o} p_{M}^{*}\right)^{1-\rho}}
$$

Verify from above that $\frac{\partial \log M^{d}(\psi)}{\partial \lambda}<0$. That is, the direct effect of a decrease in $\lambda$ is to increase imports at the firm level. It is straightforward to verify that a firm is more likely to offshore the lower the $\lambda$. The indirect effect working through $\widehat{\varphi}$ will go in the opposite direction because $\frac{d \widehat{\varphi}}{d \lambda}<0$ as shown above.

The above expressions are for the domestic sales of a firm. For exporting firms, there will be an additional term corresponding to the export sales with a similar effect. That is, the imported inputs needed in export sales is given by

$$
M^{x}=(1-\alpha)^{\rho}\left(\frac{\sigma}{\sigma-1}\right)^{-\sigma}\left(t_{o} p_{M}^{*}\right)^{-\rho} \lambda^{-\rho}\left(c_{s}(\psi)^{\rho-\sigma}\right)\left(\tau t_{x}\right)^{1-\sigma} \varphi^{\sigma-1} A
$$

Again, $\frac{\partial \log M^{x}(\psi)}{\partial \lambda}<0$.

As well, for exporting firms, we also get $\frac{\partial \log M^{x}(\psi)}{\partial \tau}<0$. That is, a decrease in output trading cost increases their exports and consequently increases their demand for imported inputs.

Note also that changes in $\tau$ affect all firms indirectly through their domestic sales because $\frac{d \log M^{d}(\psi)}{d \tau}>0$ follows from $\frac{d \widehat{\varphi}}{d \tau}<0$. That is, the import of all firms is adversely affected by a decrease in $\tau$ due to the effect of $\tau$ on $\widehat{\varphi}$. 


\subsection{Expressions for Employment}

Given the unit cost for $Y$ in (5), Shephard's lemma implies that labor requirement per unit of output for a firm with productivity $\varphi$ and offshoring status $s$ is given by $\alpha^{\rho} c_{s}(\psi)^{\rho} / \varphi$, for $s \in\{n, o\}$. Therefore, $L_{s}(\psi)=\left(\alpha^{\rho} c_{s}(\psi)^{\rho} / \varphi\right) z(\psi)$. Next, we use $(2)$ for $z(\psi)$ to get $L_{s}^{d}(\psi)=$ $\left(\alpha^{\rho} c_{s}(\psi)^{\rho} / \varphi\right) p(\psi)^{-\sigma} P^{\sigma-\eta} \mathbb{L}$ as the labor requirement to meet domestic demand. Lastly, substitute out $p(\psi)$ and $P$ using equations (6) and (9) to obtain

$$
L_{s}^{d}(\psi)=\alpha^{\rho}(\sigma-1)\left(c_{s}(\psi)^{\rho-\sigma}\right)\left(\frac{\varphi c_{n}}{\widehat{\varphi}}\right)^{\sigma-1} f \text { for } s \in\{n, o\}
$$

For exporting firms, the export demand is $z^{x}(\psi)=p^{x}(\psi)^{-\sigma} A=\left(\left(\frac{\sigma}{\sigma-1}\right) \frac{\tau t_{x} c_{s}(\psi)}{\varphi}\right)^{-\sigma} A$, therefore, they need to ship $\tau t_{x} z^{x}(\psi)$, and hence we get the following labor requirement for exports

$$
L_{s}^{x}(\psi)=\alpha^{\rho}\left(\frac{\sigma}{\sigma-1}\right)^{-\sigma} c_{s}(\psi)^{\rho-\sigma}\left(\tau t_{x}\right)^{1-\sigma} \varphi^{\sigma-1} A
$$

Combining the above, we obtain the expression for employment presented in the text. 


\section{Appendix Tables}

Table 10: The Impact of Trade Costs on Firm-Level Employment, Full Specification

\begin{tabular}{|c|c|c|c|c|c|c|}
\hline & (1) & $(2)$ & $(3)$ & (4) & $(5)$ & (6) \\
\hline $\operatorname{ITC}(\lambda)$ & $\begin{array}{c}0.009 \\
(0.006)\end{array}$ & $\begin{array}{c}0.006 \\
(0.006)\end{array}$ & $\begin{array}{c}0.011 \\
(0.007)\end{array}$ & $\begin{array}{c}0.006^{* * *} \\
(0.001)\end{array}$ & $\begin{array}{c}0.006^{* * *} \\
(0.001)\end{array}$ & $\begin{array}{c}0.005^{* * *} \\
(0.002)\end{array}$ \\
\hline $\mathrm{EXP} \times \lambda$ & & $\begin{array}{c}0.003 \\
(0.002)\end{array}$ & $\begin{array}{l}-0.004 \\
(0.003)\end{array}$ & & $\begin{array}{l}-0.001 \\
(0.001)\end{array}$ & $\begin{array}{c}-0.002 \\
(0.001)\end{array}$ \\
\hline $\mathrm{EXP} \times \mathrm{IMP} \times \lambda$ & & $\begin{array}{c}0.017^{* * *} \\
(0.001)\end{array}$ & $\begin{array}{c}0.015^{* * *} \\
(0.002)\end{array}$ & & $\begin{array}{c}0.001 \\
(0.001)\end{array}$ & $\begin{array}{c}-0.001 \\
(0.001)\end{array}$ \\
\hline $\operatorname{IMP} \times(-\sigma) \times \lambda$ & $\begin{array}{c}0.006^{* * *} \\
(0.001)\end{array}$ & $\begin{array}{c}0.006^{* * *} \\
(0.001)\end{array}$ & $\begin{array}{c}0.006^{* * *} \\
(0.001)\end{array}$ & $\begin{array}{c}0.001^{* * *} \\
(0.000)\end{array}$ & $\begin{array}{c}0.001^{\text {*** }} \\
(0.000)\end{array}$ & $\begin{array}{c}0.001^{* * *} \\
(0.000)\end{array}$ \\
\hline $\mathrm{OTC}(\tau)$ & & & $\begin{array}{l}-0.003 \\
(0.007)\end{array}$ & & & $\begin{array}{c}0.003^{* * *} \\
(0.001)\end{array}$ \\
\hline $\mathrm{EXP} \times \tau$ & & & $\begin{array}{c}0.004^{* * *} \\
(0.002)\end{array}$ & & & $\begin{array}{l}-0.000 \\
(0.001)\end{array}$ \\
\hline $\mathrm{EXP} \times \mathrm{IMP} \times \tau$ & & & $\begin{array}{c}0.002 \\
(0.002)\end{array}$ & & & $\begin{array}{c}0.001^{* *} \\
(0.001)\end{array}$ \\
\hline $\mathrm{EXP}=1$ & $\begin{array}{c}0.284^{* * *} \\
(0.010)\end{array}$ & $\begin{array}{c}0.199^{* * *} \\
(0.020)\end{array}$ & $\begin{array}{c}0.212^{\text {*** }} \\
(0.029)\end{array}$ & $\begin{array}{c}0.025^{* * *} \\
(0.005)\end{array}$ & $\begin{array}{c}0.035^{* * *} \\
(0.009)\end{array}$ & $\begin{array}{c}0.046^{* * *} \\
(0.012)\end{array}$ \\
\hline $\mathrm{IMP}=1$ & $\begin{array}{c}0.040 \\
(0.029)\end{array}$ & $\begin{array}{c}0.047 \\
(0.030)\end{array}$ & $\begin{array}{c}0.059 \\
(0.037)\end{array}$ & $\begin{array}{c}-0.003 \\
(0.012)\end{array}$ & $\begin{array}{c}-0.008 \\
(0.013)\end{array}$ & $\begin{array}{c}-0.004 \\
(0.015)\end{array}$ \\
\hline Industry FE & Yes & Yes & Yes & No & No & No \\
\hline Firm FE & No & No & No & Yes & Yes & Yes \\
\hline Year FE & Yes & Yes & Yes & Yes & Yes & Yes \\
\hline Observations & 63529 & 63529 & 63529 & 62390 & 62390 & 62390 \\
\hline
\end{tabular}

Note: All tables include year fixed effects. $\lambda$ is the modified input trade cost, $\tau$ is the output trade cost. $\rho$ is the input elasticity of substitution, $\sigma$ is the Korean output elasticity of substitution from Broda and Weinstein (2006). In columns (4) and (8), where output trade cost $(\tau)$ is also included, we have replaced ITC with ITC2 as our measure of input trade cost $(\lambda)$ to to avoid the high correlation between input and output trade cost. Standard errors are in the parentheses. $\quad{ }^{*} p<.10,{ }^{* *} p<.05,{ }^{* * *} p<.01$ 


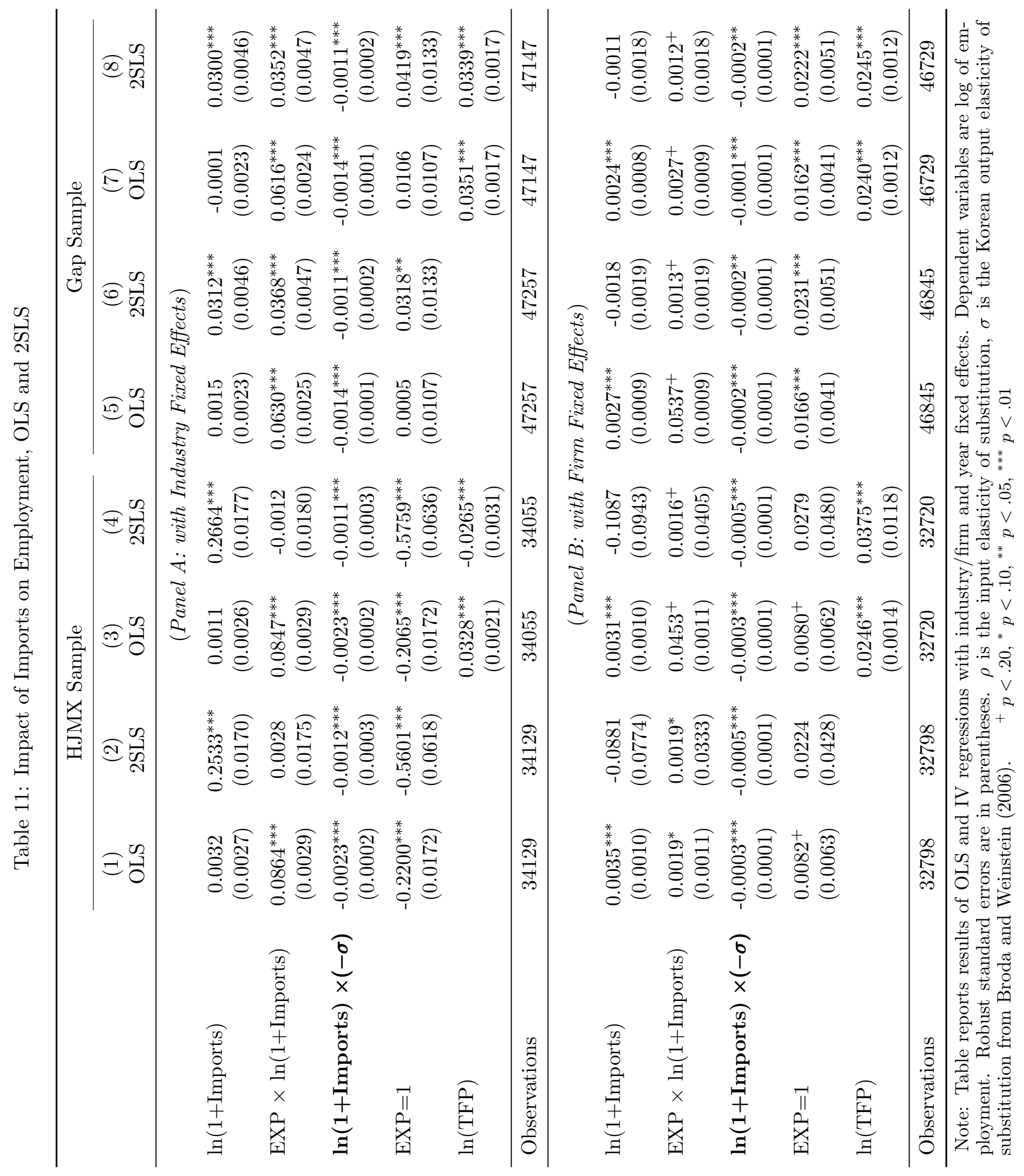


Table 12: Propensity Score Matching Estimation: Firm-Level Imports and Employment

\begin{tabular}{lcccccc}
\hline & $(1)$ & $(2)$ & $(3)$ & $(4)$ & $(5)$ & $(6)$ \\
\hline$I M P=1$ & $0.2235^{* * *}$ & $0.2019^{* * *}$ & $0.0792^{* * *}$ & $0.0257^{* * *}$ & $0.0211^{* * *}$ & 0.0126 \\
& $(0.0088)$ & $(0.0103)$ & $(0.0211)$ & $(0.0051)$ & $(0.0063)$ & $(0.0114)$ \\
$I M P \times E X P$ & & & $0.0628^{* * *}$ & & & 0.0034 \\
& & & $(0.0232)$ & & & $(0.0119)$ \\
$\boldsymbol{I M P} \times(-\boldsymbol{\sigma})$ & & $-0.0059^{* * *}$ & $-0.0057^{* * *}$ & & $-0.0013^{+}$ & $-0.0012^{+}$ \\
& & $(0.0014)$ & $(0.0014)$ & & $(0.0010)$ & $(0.0010)$ \\
$E X P=1$ & & & $0.1428^{* * *}$ & & & $0.0215^{* * *}$ \\
& & & $(0.0117)$ & & & $(0.0068)$ \\
\hline Firm FE & No & No & No & Yes & Yes & Yes \\
Year FE & Yes & Yes & Yes & Yes & Yes & Yes \\
Observations & 18138 & 18138 & 18138 & 18138 & 18138 & 18138 \\
\hline
\end{tabular}

Note: All estimations include year fixed effects. Robust standard errors in parentheses. $\rho$ is the input elasticity of substitution, $\sigma$ is the Korean output elasticity of substitution from Broda and Weinstein (2006). $\quad{ }^{+} p<.20,{ }^{*} p<.10,{ }^{* *} p<.05,{ }^{* * *} p<.01$ 